Article

\title{
Investigation on the Frictional Performance of Surface Textured Ring-Deformed Liner Conjunction in Internal Combustion Engines
}

\author{
Cheng Liu ${ }^{1,2}$, Yanjun Lu ${ }^{1,2, *}$, Yongfang Zhang ${ }^{3, *}$, Lujia Tang ${ }^{1}$, Cheng Guo ${ }^{1}$ \\ and Norbert Müller ${ }^{4}$ \\ 1 School of Mechanical and Precision Instrument Engineering, Xi'an University of Technology, \\ Xi'an 710048, China \\ 2 State Key Laboratory of Digital Manufacturing Equipment and Technology, Huazhong University of Science \\ and Technology, Wuhan 430074, China \\ 3 School of Printing, Packaging Engineering and Digital Media Technology, Xi'an University of Technology, \\ Xi'an 710048, China \\ 4 College of Engineering, Michigan State University, East Lansing, MI 48824, USA \\ * Correspondence: yanjunlu@xaut.edu.cn (Y.L.); zhangyf@xaut.edu.cn (Y.Z.); Tel.: +86-29-8231-2513 (Y.L.)
}

Received: 9 June 2019; Accepted: 15 July 2019; Published: 18 July 2019

\begin{abstract}
In internal combustion engines (ICEs), the frictional performance of ring-liner conjunction (RLC) has drawn special attention because it greatly affects the fuel efficiency of the engines. In recent years, surface texture (i.e., micro dimples or grooves) has emerged as a promising approach to improve the frictional performance of RLC. However, most current studies on surface textured RLC were conducted by assuming that the liner was ideally circular and the lubrication condition was either fully flooded or starved. In this study, to evaluate the frictional characteristics of an RLC with surface texture on the ring, a numerical model of lubrication is presented by considering the liner deformation, as well as the coexistence of the fully flooded and staved lubrication conditions in an engine cycle. On this basis, the frictional properties of a surface textured RLC are analyzed, and the impacts of the liner deformation and temperature on the friction-reducing effect of the surface texture are also evaluated. The results show that the surface texture on the ring can effectively reduce the power dissipation and friction dissipation of an RLC, and the reductions vary with the liner temperature and deformation. Large reductions in the power dissipation and friction dissipation of an RLC are obtained when the liner temperature is low or the liner deformation is small.
\end{abstract}

Keywords: surface texture; liner deformation; friction; power dissipation; temperature; mixed lubrication

\section{Introduction}

In recent years, surface texture has been regarded as an effective approach to improve the frictional performance of the ring-liner conjunction (RLC) in internal combustion engines (ICEs) [1-4]. However, for the RLC in ICEs, actual working conditions are very complex and greatly affect frictional performance $[5,6]$. Therefore, to understand the friction-reducing mechanism of the surface texture on the ring/liner more deeply, the investigation into the frictional characteristics of surface textured RLC under complex working conditions has attracted more and more attention.

During the working process of an RLC, hydrodynamic and mixed regimes of lubrication usually coexist in an engine cycle [5,7]. Hence, the hydrodynamic and mixed regimes of lubrication in the engine cycle of an RLC must be considered. Etsion et al. [8,9] conducted some research works on the friction-reducing effect of the dimple textured ring. The partially dimple textured ring was observed to have excellent frictional properties under the hydrodynamic lubrication regime. 
Caciu et al. [10] assessed the frictional characteristics of the dimple/groove textured liner. Optimal frictional properties were observed when a suitable shape and distribution were chosen for the dimple/groove. Noutary et al. [11] analyzed the oil film pressure of an RLC with different groove shapes, depths, and densities by using a multigrid code method. Groove depth and density were observed to have great influence on load-carrying capacity. Ezhilmaran et al. [12] textured laser dimples on the ring by using YAG (yttrium aluminum garnet) system. The frictional properties and oil film distribution in a textured RLC were studied experimentally and theoretically. However, these works [8-12] were mainly focused on the frictional properties of the textured RLC under the hydrodynamic regime of lubrication. The frictional properties of the textured RLC under the mixed regime of lubrication need to be further understood.

Usman et al. [13] developed a 2D mathematical model to simulate the frictional characteristics of the textured RLC under the mixed regime of lubrication by considering the realistic rheology properties of lubricant. The influence of surface texture on the frictional behaviors of an RLC was studied under warm operation conditions. Morris et al. [14] presented a combined model to predict the frictional behaviors of a laser textured RLC at piston top dead center (the regime of lubrication was mixed). The friction reduction of the RLC after surface texturing was negligible when the depth of surface texture was small. Yin et al. [15] assessed the mixed lubrication behaviors of a textured RLC under different combustion modes. The combustion mode showed a significant effect on lubrication performance. Liu et al. [16] and Söderfjäll et al. [17] proposed a mass conservative lubrication model for a dimple textured liner with a consideration of asperity contact under the mixed regime of lubrication. Based on the model, the impact of dimple geometry on the friction and power dissipation of an RLC was studied. In these works [13-17], the lubrication condition of the RLC was assumed to be fully flooded, and an isothermal condition was also considered. By considering that the oil film thermal effect caused by friction and the prevalent starved lubrication condition in an RLC, Meng and his coworkers [18-20] studied the effects of surface texture on the frictional characteristics of an RLC. Their results showed that surface texture can reduce the friction of an RLC significantly, even if the lubrication condition was starved. In the works of Meng et al. [18-20], an ideal circular liner was considered to evaluate the frictional characteristics of a surface textured RLC.

It is clear that a liner is not ideally circular, and two different conditions of lubrication (i.e., fully flooded and starved) usually coexist in an RLC engine cycle [21-23]. This is because liner deformation at assembly and service stages is inevitable [24], and the lubricant supplied to the ring is time-varying and usually insufficient at some points of the engine cycle [25]. Therefore, this study provides a comprehensive mathematical model to analyze the frictional characteristics of a groove textured RLC by considering liner deformation and the coexistence of the two different lubrication conditions in an engine cycle. Based on the model, the frictional characteristics of a groove textured RLC were analyzed for different liner deformations. Furthermore, different liner temperatures were also considered to evaluate the friction-reducing effect of ring grooves because liner temperature has great influence on lubricant viscosity [26], and different values of lubricant viscosity will result in different frictional behaviors.

\section{Mathematical Modeling}

\subsection{Geometrical Modeling}

Micro grooves are considered to be textured at the both ends of a ring because of its significant friction-reducing effect [13]. Figure 1 and Table 1 show the schematic diagram and geometry parameters of an RLC with micro grooves. To describe the geometry and distribution of the grooves, three dimensionless parameters are defined and written as [13]:

$$
\begin{aligned}
& x=\mathrm{b}_{\mathrm{t}} / \mathrm{b}, \\
& \mathrm{s}=\mathrm{r}_{\mathrm{g}} / \mathrm{r}_{\mathrm{c}},
\end{aligned}
$$




$$
\varepsilon=\mathrm{h}_{\mathrm{g}} / \mathrm{r}_{\mathrm{g}}
$$

where $\chi$ is the area ratio of groove and $\chi=0.6$ is adopted in the analysis [13]. $b_{t}$ is width of textured zone in the axial direction, $\mathrm{b}$ is the width of ring, $\mathrm{s}$ is the area density of groove, and $\varepsilon$ is the depth-to-width ratio of groove. According to previous research works [13,16], small values of the area density s (i.e., $\mathrm{s}=0.25$ ) and depth-to-width $\varepsilon$ (i.e., $\varepsilon=0.1$ ) were adopted in the current study to maximally improve the frictional characteristics. The corresponding dimensional width of groove $r_{g}$, width between two adjacent grooves $r_{c}$, and maximum depth of groove $h_{g}$ were $12.5,50$, and $1.25 \mu \mathrm{m}$ respectively.

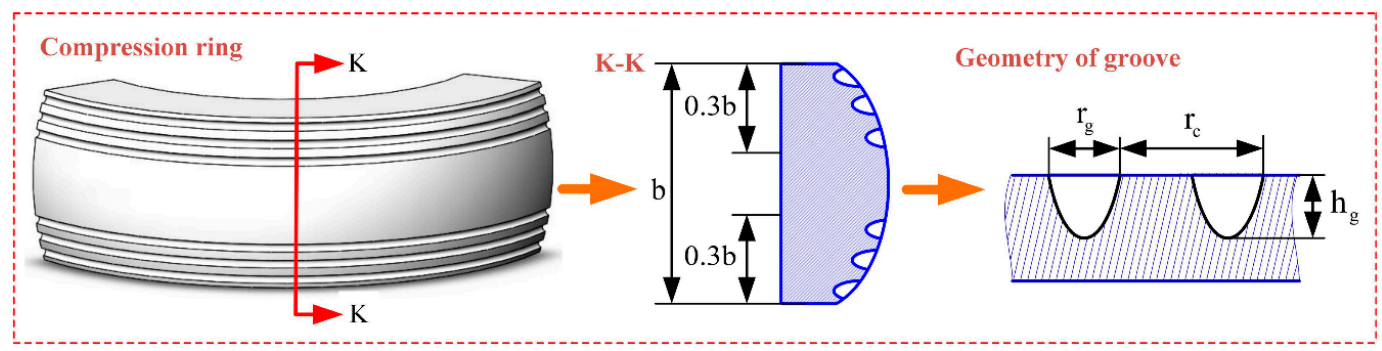

(a)

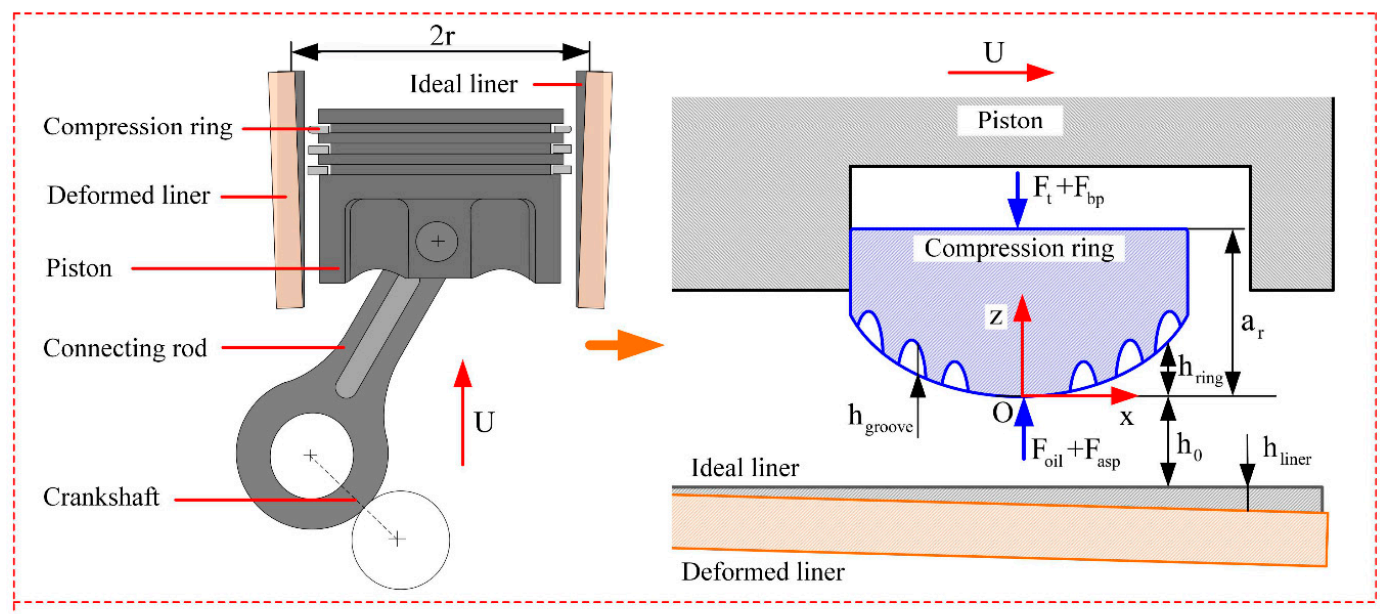

(b)

Figure 1. Schematic diagrams of the groove textured ring and ring-liner conjunction (RLC): (a) Groove textured ring; (b) groove textured RLC.

Table 1. Geometry parameters of the RLC.

\begin{tabular}{ccc}
\hline Parameter & Value & Unit \\
\hline Stroke length, $\mathrm{l}_{\mathrm{s}}$ & 90 & $\mathrm{~mm}$ \\
Axial width of ring, $\mathrm{b}$ & 1 & $\mathrm{~mm}$ \\
Thickness of ring, $\mathrm{a}_{\mathrm{r}}$ & 3.5 & $\mathrm{~mm}$ \\
Nominal radius of liner, $\mathrm{r}$ & 42 & $\mathrm{~mm}$ \\
Young's modulus of ring, $\mathrm{E}_{1}$ & 250 & $\mathrm{GPa}$ \\
Young's modulus of liner, $\mathrm{E}_{2}$ & 120 & $\mathrm{GPa}$ \\
Poisson's ratio of ring, $\tau_{1}$ & 0.3 & - \\
Poisson's ratio of liner, $\tau_{2}$ & 0.3 & - \\
Surface roughness of ring, $\sigma_{1}$ & 0.42 & $\mu \mathrm{m}$ \\
Surface roughness of liner, $\sigma_{2}$ & 0.48 & $\mu \mathrm{m}$ \\
\hline
\end{tabular}


In this study, liner deformation was considered. To describe the radius variation of the deformed liner from its ideal circular shape $\Delta \mathrm{R}_{\mathrm{cir}}$, a Fourier series was used. The Fourier series can be written as follows [27,28]:

$$
\Delta \mathrm{R}_{\mathrm{cir}}=\sum_{\mathrm{n}=0}^{\mathrm{N}}\left[\mathrm{A}_{\mathrm{n}} \cos (\mathrm{n} \varphi)+\mathrm{B}_{\mathrm{n}} \sin (\mathrm{n} \varphi)\right],
$$

To simplify the calculation, Equation (4) can be expressed as follows [28]:

$$
\Delta \mathrm{R}_{\mathrm{cir}}=\sum_{\mathrm{n}=0}^{\mathrm{N}}\left\{\frac{\Delta \mathrm{c}_{\mathrm{n}}}{2} \cos \left[\mathrm{n}\left(\varphi-\varphi_{\mathrm{n}}\right)\right]\right\}
$$

with

$$
\begin{gathered}
\Delta c_{n}=2 \sqrt{A_{n}^{2}+B_{n}^{2}}, \\
\varphi_{n}=\frac{1}{n} \arctan \frac{B_{n}}{A_{n}},
\end{gathered}
$$

where $\mathrm{n}$ is the order of liner deformation, $\mathrm{N}$ is the maximum order of liner deformation, $\varphi$ is the angular position in the circumferential direction, $\varphi_{\mathrm{n}}$ is the angle of maximum liner deformation in the circumferential direction for the order $n, \Delta c_{n}$ is the maximum liner deformation for the order $n$, and $A_{n}$ and $B_{n}$ are the Fourier coefficients for the order $n$.

Therefore, the variation of liner radius from its inscribed circle $\Delta R$ can be written as $[21,28,29]$ :

$$
\Delta \mathrm{R}=\Delta \mathrm{R}_{\mathrm{cir}}-\Delta \mathrm{R}_{\min }
$$

where $\Delta \mathrm{R}_{\min }$ is the minimum variation in the liner radius.

In generally, $\Delta \mathrm{R}_{\text {cir }}$ can be modeled accurately by using a Fourier series with first few orders (i.e., $\mathrm{n}=$ $0,1,2,3,4$ or $N=4$ ) [27]. However, under working conditions, due to tension force and backpressure, the ring also elastically deforms to accommodate the radial radius variation of the liner when the liner is deformed, and the clearance between the ring and liner caused by the liner deformation after considering the elastic deformation of ring is mainly the outcome of the liner deformation with $\mathrm{n}=4$ [21]. Therefore, only $\mathrm{n}=4$ was considered in this and previous studies [21,25,28-30]. Figure 2 shows the deformed liner with $\mathrm{n}=4$.

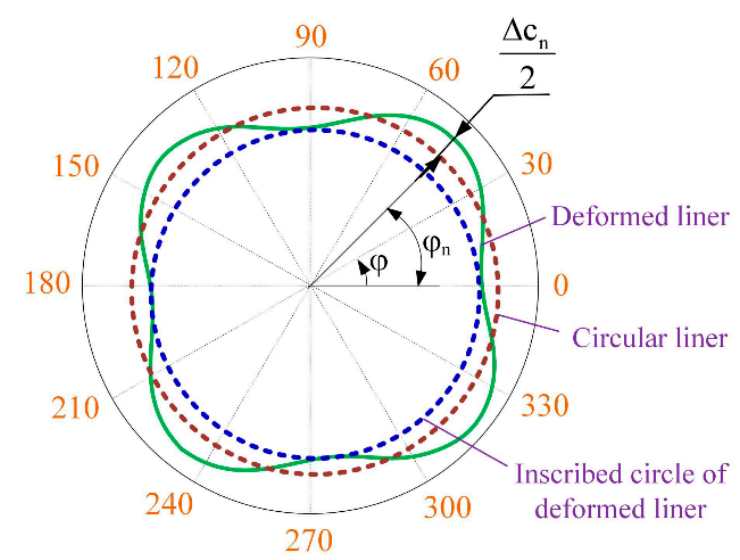

Figure 2. Schematic diagram of the deformed liner for any cross section in the axial direction.

It should be noted that the maximum liner deformation $\Delta c_{n}$ (or the values of the Fourier coefficients $A_{n}$ and $B_{n}$ ) must be known in advance to model the liner deformation. Generally, the values of $A_{n}$ and $B_{n}$ can be obtained from a Fourier analysis on the measured profile of the deformed liner or on the simulated profile of the deformed liner (e.g., finite element simulation) [27]. However, the measurement and finite element simulation on the deformed liner profile is relatively complex 
and time consuming $[27,28]$. Furthermore, according to the work of Zhu et al. [31], for the liner deformation with $n=4$, there is a small variation of the profile in the axial direction under some conditions. Therefore, in the simulation of liner deformation by using the Fourier series, it is usually assumed that the profile shape of the deformed liner remains the same in the axial direction for analysis convenience and time saving $[22,25,29]$. Hence, the profile of the deformed liner can be modeled by a Fourier series with a given value of $\Delta c_{n}[21,25,28-30]$. In this study, according to the previous works [28,30], $\Delta c_{n}$ with a maximum value of $30 \mu \mathrm{m}$ was considered for $\mathrm{n}=4$.

In general, ring elastic deformation reduces the clearance between the ring and liner caused by liner deformation. Therefore, a clearance in the RLC caused by a 4 th order deformation of liner $\mathrm{h}_{\text {liner }}$ can be expressed as $[21,25,29]$ :

$$
\mathrm{h}_{\text {liner }}=\left.\Delta \mathrm{R}\right|_{\mathrm{n}=4}-\Delta \delta
$$

where $\Delta \delta$ is the elastic deformation of the ring when the order $n$ is 4 , and it can be written as [25,29]:

$$
\Delta \delta=\frac{3\left(F_{t}+F_{b p}\right) r^{2}\left(2 r-a_{r}\right)^{2}}{225 E_{1} b_{r}^{3}}
$$

where $a_{r}$ is the axial thickness of ring, $F_{t}$ and $F_{b p}$ are the tension force and back pressure of ring, $\mathrm{E}_{1}$ represents the Young's modulus of ring, and $\mathrm{r}$ is the nominal liner radius.

\subsection{Governing Equation}

For the groove textured RLC, the average Reynolds equation and the JFO (Jacoboson-Floberg-Olsson) cavitation boundary condition are combined to analyze frictional behaviors. It is written as follows [32]:

$$
\frac{\partial}{\partial x}\left(\phi_{x} \frac{\rho h^{3}}{\mu} \frac{\partial p}{\partial x}\right)+\frac{\partial}{\partial y}\left(\phi_{y} \frac{\rho h^{3}}{\mu} \frac{\partial p}{\partial y}\right)=6 \mathrm{U} \phi_{c} \frac{\partial[(1-\varepsilon) \rho h]}{\partial x}+6 U \sigma \frac{\partial\left[(1-\varepsilon) \rho \phi_{s}\right]}{\partial x}+12 \phi_{c} \frac{\partial[(1-\varepsilon) \rho h]}{\partial t}
$$

with

$$
\left\{\begin{array}{l}
\mathrm{p}>\mathrm{p}_{\mathrm{c}} \Rightarrow \varepsilon=0 \\
\varepsilon>0 \Rightarrow p=\mathrm{p}_{\mathrm{c}} \\
0 \leq \varepsilon \leq 1
\end{array}\right.
$$

where $\rho$ is the density of lubricant, $\mu$ is the lubricant viscosity, $\mathrm{p}$ is the lubricant pressure, $\mathrm{t}$ is the time, $\sigma$ is the composite roughness of the RLC, $\mathrm{U}$ is the ring velocity, and $\mathrm{h}$ is the thickness of lubricant between the groove textured ring and liner. $\varepsilon$ is the cavity fraction, and more discussion on the cavity fraction $\varepsilon$ is provided in the work of $\mathrm{Gu}$ et al. [32]. $\mathrm{p}_{\mathrm{c}}$ is the cavity pressure, and it was assumed to be zero according to the reported works $[2,20,23]$. $\phi_{\mathrm{x}}$ and $\phi_{\mathrm{y}}$ are the pressure flow coefficients in the $\mathrm{x}$ and $\mathrm{y}$ directions, $\phi_{\mathrm{s}}$ and $\phi_{\mathrm{c}}$ are the coefficients of shear flow and contact flow; they can be calculated by using the classic $\mathrm{P}$ and $\mathrm{C}$ (Patir and Cheng) method $[33,34]$ and $\mathrm{W}$ and $\mathrm{Z}$ (Wu and Zheng) method [35], respectively. These methods have been widely used in the simulation of RLCs with rough surfaces because they have the advantages of low cost in computation time and easy realization $[20,36]$. According to the $\mathrm{P}$ and $\mathrm{C}$ method and the $\mathrm{W}$ and $\mathrm{Z}$ method, the pressure flow, shear flow, and contact flow coefficients can be written as follows:

$$
\begin{gathered}
\phi_{x}=1-0.9 \mathrm{e}^{-0.56 \lambda} \text { if } \lambda>0.5 \\
\phi_{\mathrm{y}}=1-0.9 \mathrm{e}^{-0.56 \lambda} \text { if } \lambda>0.5 \\
\phi_{\mathrm{s}}= \begin{cases}1.899 \lambda^{0.98}\left(\sigma_{1}^{2} / \sigma^{2}-\sigma_{2}^{2} / \sigma^{2}\right) \mathrm{e}^{\left(-0.92 \lambda+0.05 \lambda^{2}\right)} & \text { if } \lambda \leq 5 \\
1.126\left(\sigma_{1}^{2} / \sigma^{2}-\sigma_{2}^{2} / \sigma^{2}\right) \mathrm{e}^{-0.25 \lambda} & \text { if } \lambda>5\end{cases} \\
\phi_{\mathrm{c}}= \begin{cases}\mathrm{e}^{-0.6912+0.782 \lambda-0.304 \lambda^{2}+0.0401 \lambda^{3}} & \text { if } 0 \leq \lambda<3 \\
1 & \text { if } \lambda \geq 3\end{cases}
\end{gathered}
$$


with

$$
\begin{gathered}
\sigma=\sqrt{\sigma_{1}^{2}+\sigma_{2}^{2}} \\
\lambda=h / \sigma
\end{gathered}
$$

where $\sigma_{1}$ and $\sigma_{2}$ are the surface roughness of ring and liner and $\lambda$ is the ratio of lubricant thickness.

The thickness of lubricant between the groove textured ring and liner $\mathrm{h}$ can be written as follows:

$$
\mathrm{h}=\mathrm{h}_{0}+\mathrm{h}_{\text {groove }}+\mathrm{h}_{\text {liner }}+\mathrm{h}_{\text {ring }}
$$

where $\mathrm{h}_{0}$ is the minimum clearance in the $\mathrm{RLC}, \mathrm{h}_{\text {groove }}$ is the clearance caused by the groove, $\mathrm{h}_{\text {ring }}$ is the clearance related to the ring profile, and their expressions have been given in the reported works $[3,16,25]$.

\subsection{Lubrication Condition}

Besides the fully flooded condition of lubrication, the starved condition of lubrication can be also observed at some crank angles in the engine cycle because the lubricant supplied to the RLC is usually insufficient $[18,19]$. Figure 3 shows the different conditions of the lubrication for the RLC. It should be noted that different lubrication conditions mean different boundary positions of the lubrication zone. Therefore, in order to solve the instant boundary positions (i.e., inlet position and outlet position) and then determine the instant lubrication condition, an oil transport model has been proposed, as shown in Figure 4. In Figure 4, two control volumes at the inlet and outlet of lubrication zone (i.e., front control volume and back control volume) are presented. For the front control volume, the average inflow rate of lubricant $q_{\text {in_ave }}$ and the average outflow rate of lubricant $q_{\text {en_ave }}$ within a time step $\Delta t$ can be expressed as:

$$
\begin{gathered}
\mathrm{q}_{\mathrm{in} \_ \text {ave }}=\frac{\mathrm{Uh}_{\mathrm{in}}+\mathrm{U}^{0} \mathrm{~h}_{\mathrm{in}}^{0}}{2} \\
\mathrm{q}_{\text {en_ave }}=\frac{\mathrm{q}_{\mathrm{en}}+\mathrm{q}_{\mathrm{en}}^{0}}{2}
\end{gathered}
$$

where $h_{\text {in }}$ is the lubricant entry height, superscript 0 represents the variables at the previous moment, and $\mathrm{q}_{\mathrm{en}}$ is the outflow rate of lubricant for the front control volume [18].

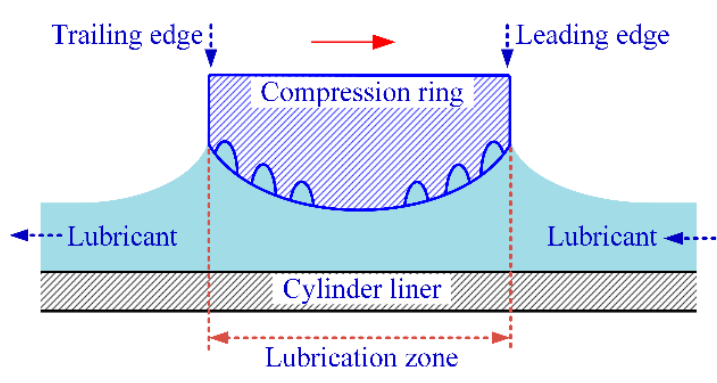

(a)

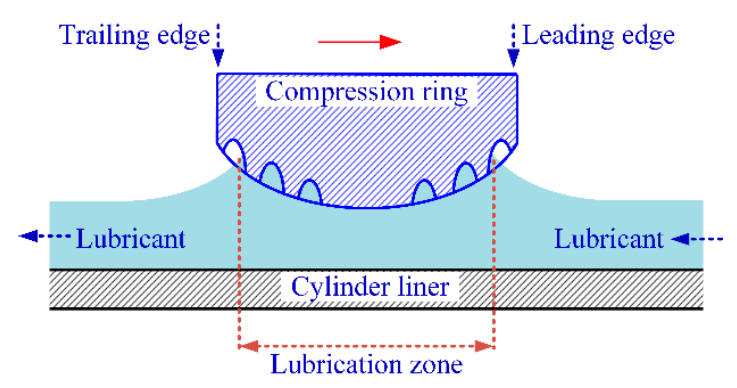

(b)

Figure 3. Schematic diagram of lubrication condition: (a) Fully flooded lubrication condition; (b) Starved lubrication condition. 


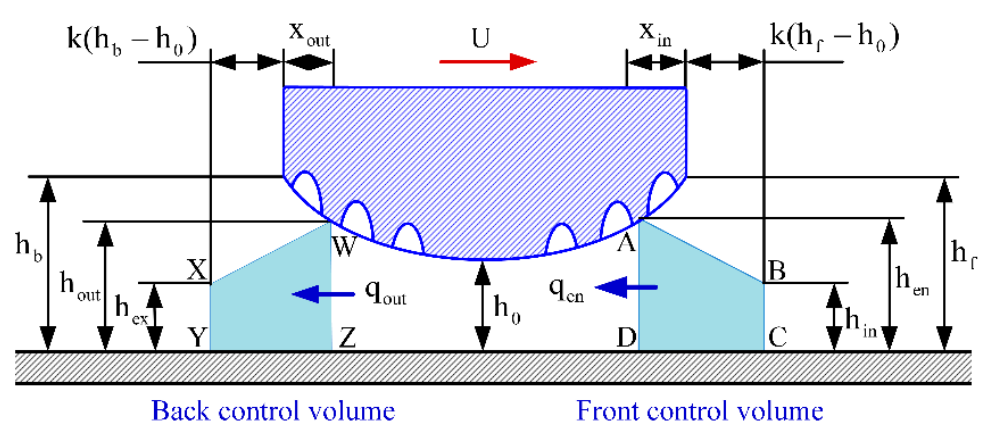

Figure 4. Schematic diagram of the oil transport model.

It should be noticed that the lubricant which flows into the front control volume is usually less than the lubricant which flows out of the front control volume [23]. Hence, the flow rate of lubricant in the front control volume changes within a time step $\Delta \mathrm{t}$. The average variation of the lubricant flow rate in the front control volume $\mathrm{q}_{\text {front_ave }}$ can be written as [23]:

$$
\mathrm{q}_{\text {front_ave }}=\frac{\left(\mathrm{V}_{\mathrm{ABCD}}-\mathrm{V}_{\mathrm{A}^{0} \mathrm{~B}^{0} \mathrm{C}^{0} \mathrm{D}^{0}}\right)}{\Delta \mathrm{t}}
$$

where $\mathrm{V}_{\mathrm{ABCD}}$ is the area for the front control volume. It can be given by:

$$
\mathrm{V}_{\mathrm{ABCD}}=\frac{\mathrm{h}_{\mathrm{in}}+\mathrm{h}_{\mathrm{en}}}{2}\left[\mathrm{k}\left(\mathrm{h}_{\mathrm{f}}-\mathrm{h}_{0}\right)+\mathrm{x}_{\mathrm{in}}\right]
$$

where $h_{e n}$ and $x_{i n}$ are the inlet clearance and width, $k$ is the aspect ratio, and $h_{f}$ represents the clearance at the leading edge of ring.

According to the principle of flow conservation, a flow balance equation should be satisfied for the front control volume [37]. The flow balance equation is given as:

$$
\mathrm{q}_{\text {in_ave }}-\mathrm{q}_{\text {en_ave }}=\mathrm{q}_{\text {front_ave }}
$$

By submitting Equations (20) (22) into Equation (24), the following expression can be obtained.

$$
\frac{\left(\mathrm{Uh}_{\mathrm{in}}+\mathrm{U}^{0} \mathrm{~h}_{\mathrm{in}}^{0}\right)-\left(\mathrm{q}_{\mathrm{en}}+\mathrm{q}_{\mathrm{en}}^{0}\right)}{2} \Delta \mathrm{t}=\mathrm{V}_{\mathrm{ABCD}}-\mathrm{V}_{\mathrm{A}^{0} \mathrm{~B}^{0} \mathrm{C}^{0} \mathrm{D}^{0}}
$$

For the back control volume, a similar flow balance equation can be also written as follows:

$$
\mathrm{q}_{\text {out_ave }}-\mathrm{q}_{\text {ex_ave }}=\mathrm{q}_{\text {back_ave }}
$$

where qout_ave $_{\text {and }}$ qex_ave are the average inflow rate and average outflow rate of lubricant for the back control volume, qback_ave is the average variation of lubricant flow rate in the back control volume, and their expressions can be written as follows:

$$
\begin{gathered}
\mathrm{q}_{\text {out_ave }}=\frac{\mathrm{q}_{\text {out }}+\mathrm{q}_{\text {out }}^{0}}{2} \\
\mathrm{q}_{\text {ex_ave }}=\frac{\mathrm{Uh}_{\mathrm{ex}}+\mathrm{U}^{0} \mathrm{~h}_{\mathrm{ex}}^{0}}{2} \\
\mathrm{q}_{\text {back_ave }}=\frac{\mathrm{V}_{\mathrm{WXYZ}}-\mathrm{V}_{\mathrm{W}^{0} \mathrm{X}^{0} \mathrm{Y}^{0} \mathrm{Z}^{0}}}{\Delta \mathrm{t}}
\end{gathered}
$$


where $q_{\text {out }}$ and $h_{\text {ex }}$ are the inflow rate and exit height of lubricant for the back control volume. $V_{W X Y Z}$ is the area of the back control volume, and its expression is written as [37]:

$$
V_{\text {WXYZ }}= \begin{cases}k\left(h_{b}-h_{0}\right)\left(\frac{h_{b}+h_{\text {ex }}}{2}\right) & \text { if } h_{\text {ex }} \geq h_{0} \\ k\left(h_{\text {out }}-h_{\text {ex }}\right)\left(\frac{h_{\text {out }}+h_{\text {ex }}}{2}\right) & \text { if } \frac{h_{0}}{10} \leq h_{\text {ex }}<h_{0} \\ {\left[k\left(h_{b}-h_{0}\right)+x_{\text {out }}\right] h_{\text {ex }}+\frac{k}{2}\left(h_{\text {out }}-\frac{h_{0}}{10}\right)^{2}} & \text { if } h_{\text {ex }}<\frac{h_{0}}{10}\end{cases}
$$

where $h_{\text {out }}$ and $x_{\text {out }}$ are the outlet clearance and outlet width and $h_{b}$ represents the clearance at the trailing edge of ring.

By submitting Equations (27) (29) into Equation (26), the following expression can be obtained.

$$
\frac{\left(\mathrm{q}_{\text {out }}+\mathrm{q}_{\mathrm{out}}^{0}\right)-\left(\mathrm{Uh}_{\mathrm{ex}}+\mathrm{U}^{0} \mathrm{~h}_{\mathrm{ex}}^{0}\right)}{2} \Delta \mathrm{t}=\mathrm{V}_{\mathrm{WXYZ}}-\mathrm{V}_{\mathrm{W}^{0} \mathrm{X}^{0} \mathrm{Y}^{0} \mathrm{Z}^{0}}
$$

By solving Equations (25) and (31), the inlet width $x_{\text {in }}$ and outlet width $x_{\text {out }}$ can be obtained, and the instant lubrication condition can be determined. In details, the lubrication condition is fully flooded when $x_{\text {in }}$ and $x_{\text {out }}$ are zero. Otherwise, the lubrication condition is starved. Furthermore, the boundary condition of the governing equation (i.e., Equation (11)) can be also given as follows:

$$
\left\{\begin{array}{l}
\left.\mathrm{p}\right|_{x=\frac{b}{2}-x_{\text {in }}}=\mathrm{p}_{\text {in }} \\
\left.\mathrm{p}\right|_{x=-\frac{b}{2}+x_{\text {out }}}=\mathrm{p}_{\text {out }}
\end{array}\right.
$$

where $p_{\text {in }}$ and $p_{\text {out }}$ are the pressures of lubricant at the boundary positions of the lubrication zone. On the intake stroke and power stroke, $p_{\text {in }}$ is the gas pressure under the ring and $p_{\text {out }}$ is the pressure in cylinder. However, on the compression stroke and exhaust stroke, $p_{\text {in }}$ is the pressure in cylinder and pout is the gas pressure under the ring.

\subsection{Thermal Effect of Lubricant}

During the working process of the RLC, the generated friction heat will raise the lubricant temperature. The temperature rise of the lubricant changes the density and viscosity, and it then greatly affects the frictional characteristics of the RLC. To determine the temperature rise of the lubricant, an analytical thermal model [38] was used in the current study. According to the model, the temperature of lubricant $\mathrm{T}_{\text {oil }}$ can be written as follows:

$$
T_{\text {oil }}=\frac{R_{\text {liner }} R_{\text {oil }} T_{\text {ring }}+R_{\text {liner }} R_{\text {ring }} T_{0}+R_{\text {ring }} R_{\text {oil }} T_{\text {liner }}+R_{\text {liner }} R_{\text {ring }} R_{\text {oil }} Q}{R_{\text {ring }} R_{\text {oil }}+R_{\text {liner }} R_{\text {oil }}+R_{\text {liner }} R_{\text {ring }}}
$$

where $R_{\text {liner }}$ is the thermal conductive flow barrier of the liner, $R_{\text {ring }}$ is the thermal conductive flow barrier of the ring, and $R_{\text {oil }}$ is the thermal conductive flow barrier of the lubricant. $T_{\text {ring }}$ and $T_{\text {liner }}$ are the temperatures on the ring surface and liner surface. $T_{0}$ is the lubricant temperature at the inlet of lubrication zone, $\mathrm{Q}$ is the flow rate of friction heat, and the expressions of $\mathrm{T}_{0}$ and $\mathrm{Q}$ can be written as [38]:

$$
\begin{gathered}
\mathrm{T}_{0}=\frac{\mathrm{T}_{\text {liner }} \mathrm{U}_{\text {liner }}+\mathrm{T}_{\text {ring }} \mathrm{U}}{\mathrm{U}_{\text {liner }}+\mathrm{U}} \\
\mathrm{Q}=\left|\mathrm{f}_{\text {total }} \mathrm{U}\right|
\end{gathered}
$$

where $\mathrm{U}_{\text {liner }}$ is velocity of the liner and $\mathrm{f}_{\text {total }}$ is the total friction force of the RLC.

After calculating the lubricant temperature $\mathrm{T}_{\text {oil }}$ (Equation (33)) and pressure $\mathrm{p}$ (Equation (11)), the lubricant density $\rho$ and viscosity $\mu$ can be evaluated by [38]:

$$
\mu=\left[\alpha_{0} \exp \left(\frac{\alpha_{1}}{\alpha_{2}+\mathrm{T}_{\text {oil }}}\right)\right] \exp \left\{\left(\ln \left[\alpha_{0} \exp \left(\frac{\alpha_{1}}{\alpha_{2}+\mathrm{T}_{\text {oil }}}\right)\right]+9.67\right)\left[-1+\left(1+5.1 \times 10^{-9} \mathrm{p}\right)^{0.68}\right]\right\},
$$




$$
\rho=\rho_{0}\left(1+\frac{0.6 \times 10^{-9} \mathrm{p}}{1+1.7 \times 10^{-9} \mathrm{p}}\right)\left[1-6.5 \times 10^{-4}\left(\mathrm{~T}_{\text {oil }}-\mathrm{T}_{\text {ref }}\right)\right],
$$

where $T_{\text {ref }}$ is reference temperature, $\alpha_{0}, \alpha_{1}$, and $\alpha_{2}$ are the correlation factors, and $\rho_{0}$ is the reference density of lubricant. The lubricant parameters are given in Table 2.

Table 2. Parameters of lubricant.

\begin{tabular}{ccc}
\hline Parameters & Value & Unit \\
\hline correlation factor, $\alpha_{0}$ & 0.06782 & $\mathrm{mPa} \cdot \mathrm{s}$ \\
correlation factor, $\alpha_{1}$ & 880.29 & ${ }^{\circ} \mathrm{C}$ \\
correlation factor, $\alpha_{2}$ & 103.08 & ${ }^{\circ} \mathrm{C}$ \\
Reference density of lubricant at $40{ }^{\circ} \mathrm{C}, \rho_{0}$ & 771.02 & $\mathrm{~kg} \cdot \mathrm{m}^{-3}$ \\
Reference viscosity of lubricant at $40{ }^{\circ} \mathrm{C}, \mu_{0}$ & 31.87 & $\mathrm{mPa} \cdot \mathrm{s}$ \\
\hline
\end{tabular}

\subsection{Frictional Characteristics}

The total friction force in the RLC $\mathrm{f}_{\text {total }}$ can be written as follows [25]:

$$
\mathrm{f}_{\text {total }}=\mathrm{f}_{\mathrm{oil}}+\mathrm{f}_{\mathrm{asp}}
$$

with

$$
\begin{gathered}
\mathrm{f}_{\mathrm{oil}}=\iint_{\Omega}(1-\varepsilon)\left\{-\frac{\mu \mathrm{U}}{\mathrm{h}}\left(\varphi_{\mathrm{f}}+\varphi_{\mathrm{fs}}\right)+\frac{\mathrm{h}}{2} \frac{\partial \mathrm{p}}{\partial \mathrm{x}} \varphi_{\mathrm{fp}}\right\} \mathrm{d} \Omega, \\
\mathrm{f}_{\mathrm{asp}}=\tau_{0} \mathrm{~A}_{\mathrm{c}}+\alpha_{\mathrm{a}} \mathrm{F}_{\mathrm{asp}}
\end{gathered}
$$

where $f_{o i l}$ and $f_{a s p}$ are the hydrodynamic and boundary friction forces; $\Omega$ represents the zone of lubrication; $\varphi_{\mathrm{f}}, \varphi_{\mathrm{fs}}$, and $\varphi_{\mathrm{fp}}$ represent the coefficients related to the friction; $\tau_{0}$ and $\alpha_{\mathrm{a}}$ are the factors of asperity shear stress and boundary friction; and $A_{c}$ and $F_{a s p}$ represent the apparent area and force of asperity contact. In the current study, the GT (Greenwood and Tripp) model was used to calculate the apparent contact area $\mathrm{A}_{\mathrm{c}}$ and contact force $\mathrm{F}_{\mathrm{asp}} \cdot[16,19]$ :

$$
\begin{gathered}
\mathrm{A}_{\mathrm{c}}=\pi^{2}(\kappa \beta \sigma)^{2} \mathrm{AF}_{2}(\lambda), \\
\mathrm{F}_{\mathrm{asp}}=\iint_{\Omega} \frac{16 \sqrt{2}}{15} \pi(\kappa \beta \sigma)^{2} \mathrm{E}^{\prime} \sqrt{\frac{\sigma}{\beta}} \mathrm{F}_{2.5}(\lambda) \mathrm{d} \Omega,
\end{gathered}
$$

where $\mathrm{A}$ is the area of asperity contact, $\mathrm{k}$ represents the density of asperities, $\beta$ represents the mean radius of asperity curvature, and the values of $\kappa \beta \sigma$ and $\sigma / \beta$ are 0.04 and 0.001 , respectively. $F_{2.5}(\lambda)$ and $\mathrm{F}_{2}(\lambda)$ are the distribution functions of the asperity heights, and their expressions can be referred to in the work of [19]. $E^{\prime}$ is the equivalent elastic modulus, and it can be expressed by:

$$
\mathrm{E}^{\prime}=\frac{1}{\frac{1-\tau_{1}^{2}}{\mathrm{E}_{1}}+\frac{1-\tau_{2}^{2}}{\mathrm{E}_{2}}}
$$

where $\tau_{1}$ is the Poisson's ratio of ring, $E_{2}$ and $\tau_{2}$ are the Young's modulus and Poisson's ratio of liner, and their values are provided in Table 1.

Furthermore, the power dissipation $\mathrm{P}_{\text {loss }}$ and friction mean effective pressure (FMEP-adopted to predict the friction dissipation) were also evaluated, and their expressions are as follows [19]:

$$
\begin{gathered}
\mathrm{P}_{\text {loss }}=\left|\mathrm{f}_{\text {total }} \mathrm{U}\right|, \\
\text { FMEP }=\frac{\int \mathrm{f}_{\text {total }} \mathrm{dl}_{\mathrm{s}}}{\mathrm{V}_{\mathrm{d}}},
\end{gathered}
$$


where $l_{s}$ is length of stroke and $V_{d}$ is the distance between the ring and top dead center of piston.

\section{Numerical Procedure}

In order to simulate the frictional performance of the RLC with grooves, a Matlab program was developed to solve the presented numerical model. Figure 5 shows the calculation flow chart for the numerical model of the RLC.

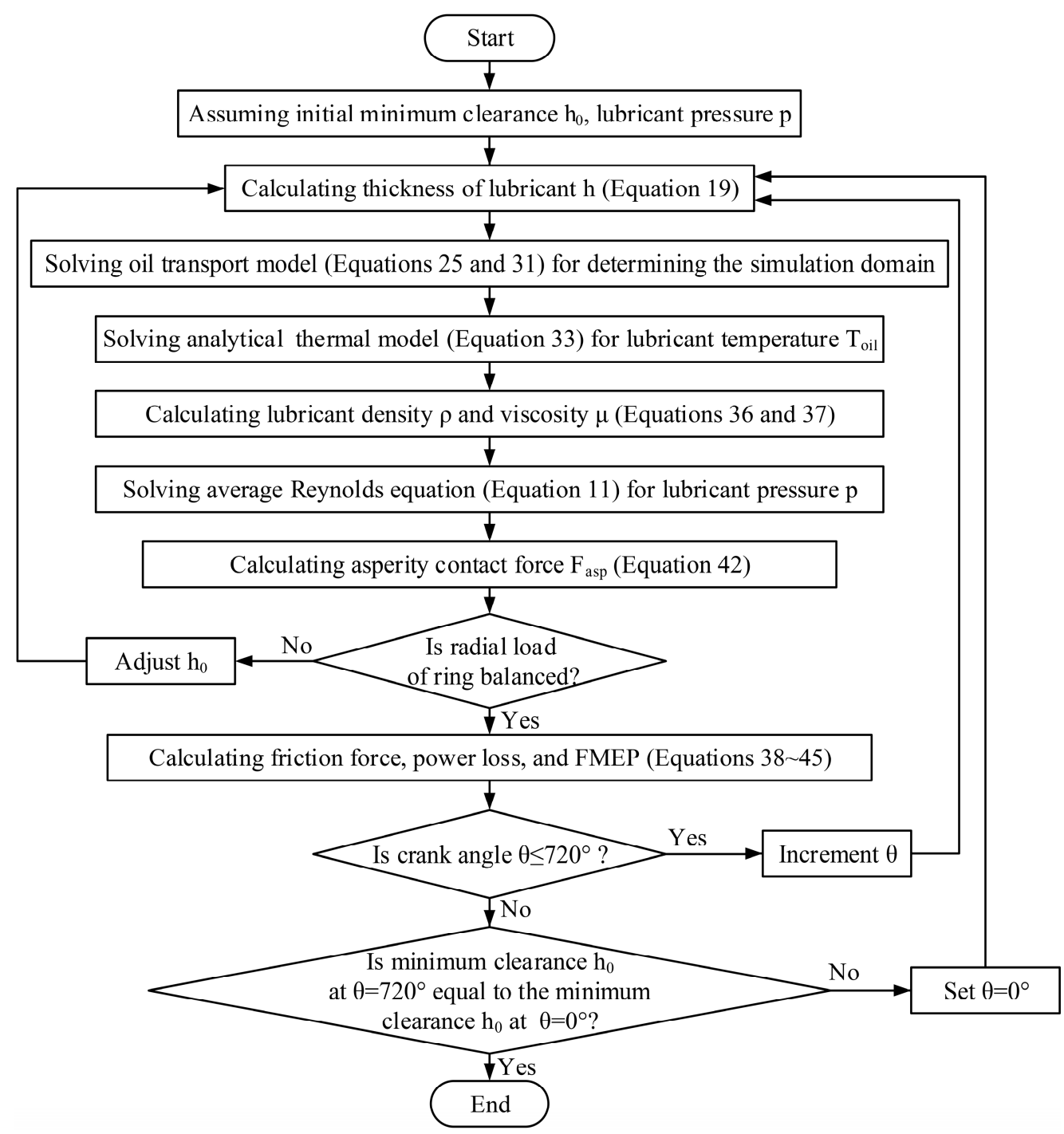

Figure 5. Calculation flow chart for the numerical model.

At any crank angle, the average Reynolds equation (i.e., Equation (11)) can be solved by the finite difference method (FDM) [39,40]. The central and backward difference schemes were used to discrete the left and right terms of the average Reynolds equation. More detailed discussions on the solving procedure of the average Reynolds equation with the JFO cavitation boundary condition can be seen in the works of Pu et al. [39] and Wang et al. [40]. In the simulation, the axial boundary positions of lubrication zone could be determined by the oil transport model (i.e., Equations (25) and (31)), and then the simulation domain in the axial direction could be expressed as $x_{\text {out }}-b / 2 \leq x \leq b / 2-x_{i n}$. In the circumferential direction, the entire length of ring was considered as the simulation domain. Furthermore, a mesh grid of $600 \times 200$ was adopted to simulate frictional performance. To illustrate the rationality of the mesh grid, the FMEP values of the RLC with grooves were calculated for two mesh grids (i.e., the mesh grid of $600 \times 200$ and the mesh grid of $800 \times 300$ ), and only about $1.0 \%$ difference 
in the FMEP values between the two mesh grids was observed. This indicates that the mesh grid of $600 \times 200$ could be used to simulate the frictional performance of the RLC with grooves.

\section{Results and Discussion}

\subsection{Validation of Model}

To illustrate the reasonability of the presented numerical model, the minimum clearance in the RLC was calculated by the present model, and this was compared with the published result from Gu et al. [41], as shown in Figure 6. The parameters adopted in the calculation were consistent with the reference of [41]. In Figure 6, the minimum clearance calculated by the current model matches well with the result of $\mathrm{Gu}$ et al. [41], and the maximum difference in the minimum clearance was about $1.0 \%$. This indicates that the presented model can be adopted to reasonably simulate the frictional behaviors of the RLC. Therefore, the frictional characteristics of the textured RLC were analyzed by using the presented model in the following sections. In the simulation, the pressure in cylinder and the sliding velocity of ring are given in Figure 7.

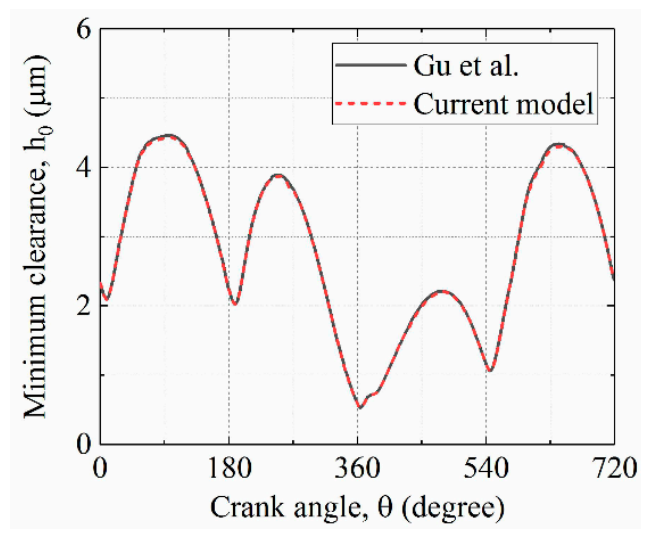

Figure 6. Minimum clearances calculated by the current model and the model of Gu et al. [41].

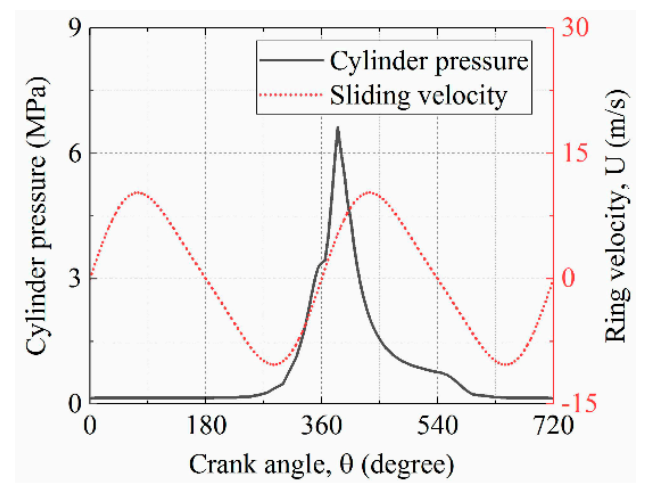

Figure 7. Pressure in cylinder and ring velocity adopted in the simulation.

\subsection{Effect of Liner Deformation}

To study the effects of liner deformation on the frictional characteristics of the groove textured RLC, the friction force, power dissipation, and friction dissipation were calculated for different maximum liner deformations. Moreover, the inlet width of lubrication zone was also calculated to evaluate the inlet condition of the lubrication because it significantly affected the frictional characteristics of the RLC $[18,19]$.

Figure 8 shows the hydrodynamic friction force and boundary friction force in the groove textured RLC for different maximum liner deformations. Compared with the groove textured RLC with ideal circular liner (i.e., the value of $\Delta \mathrm{c}$ is $0 \mu \mathrm{m}$ ), small hydrodynamic friction force and large boundary friction force were observed for the groove textured RLC with the deformed liner. Furthermore, 
the hydrodynamic friction force decreased and the boundary friction force increased with the increase of the maximum liner deformation. It is also observed from Figure 8 that the decrease of hydrodynamic friction force is obvious when the crank angles were $90,270,450$, and $630^{\circ}$ (i.e., at the middle of the strokes). The results in Figure 8 indicate that the hydrodynamic friction force and boundary fiction force in the groove textured RLC were greatly affected by the liner deformation.

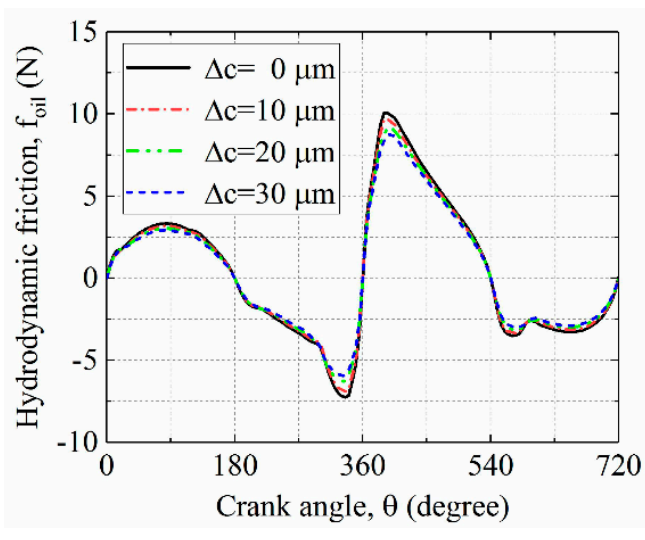

(a)

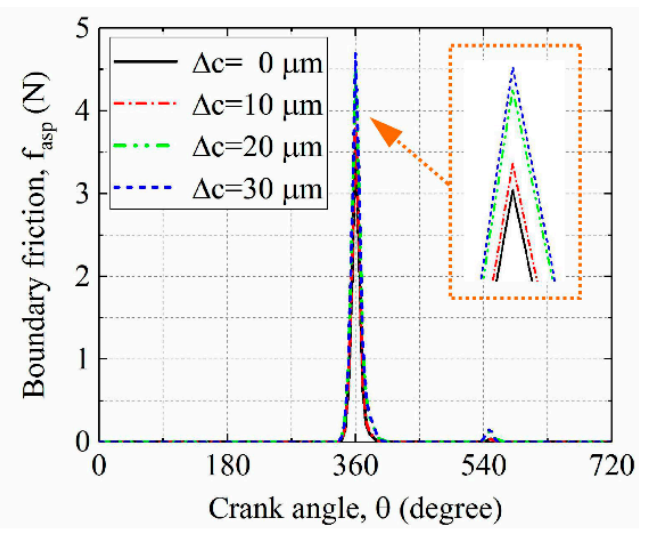

(b)

Figure 8. Friction forces in the groove textured RLC for different maximum deformations of liner: (a) Hydrodynamic friction force; (b) boundary friction force.

Figure 9 shows the power dissipation and inlet width of lubrication zone. The result shows that the maximum liner deformation had a great influence on the power dissipation, especially at the middle of the strokes. Moreover, it can be also seen that the leading edge of ring was fully flooded (i.e., the inlet width $x_{\text {in }}$ was $0 \mathrm{~mm}$ ) when the ring was near the dead centers or on the power stroke (i.e., the crank angle $360^{\circ} \leq \theta \leq 540^{\circ}$ ). However, when the ring operated near the middle of intake stroke (i.e., the crank angle $\theta=90^{\circ}$ ), compression stroke (i.e., the crank angle $\theta=270^{\circ}$ ), and exhaust stroke (i.e., the crank angle $\theta=630^{\circ}$ ), the lubrication condition at the leading edge of the ring was starved, and the degree of starved lubrication was a decreasing function of the maximum liner deformation. This is because that the inlet width of the lubrication zone is a decreasing function of the maximum liner deformation.

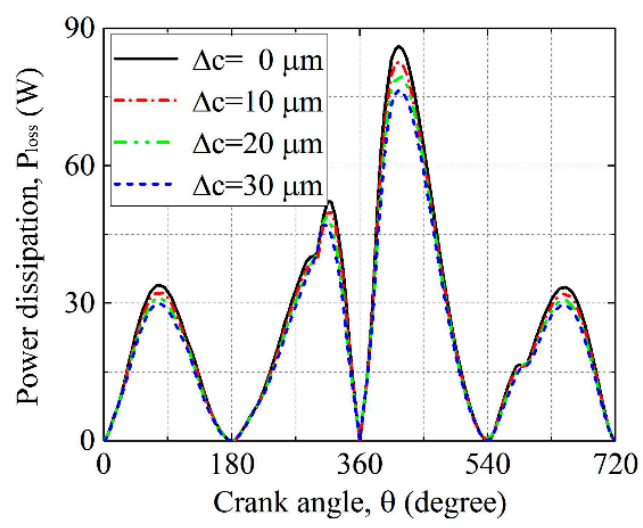

(a)

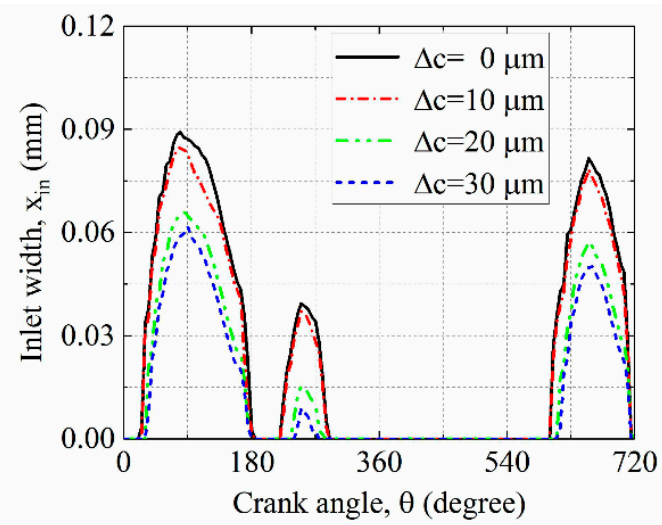

(b)

Figure 9. Power dissipation and inlet widths of lubrication zone of the groove textured RLC for different maximum liner deformations: (a) Power dissipation; (b) inlet width.

The friction-reducing effect of the grooves on the ring was also evaluated for different maximum liner deformations. Figure 10 gives the hydrodynamic friction forces in the groove textured RLC and 
untextured RLC. The hydrodynamic friction force decreased significantly when the grooves were textured on the ring. Furthermore, a large reduction of hydrodynamic friction force was obtained at the middle of the strokes, and the reduction percentages are shown in Table 3. From Table 3, it is observed that the difference in the reduction percentage of the hydrodynamic friction force among different maximum liner deformations was small. Relatively, a large reduction percentage in the hydrodynamic friction force was observed when the maximum liner deformation was $10 \mu \mathrm{m}$ or the ring operated on the power stroke. This means that the reduction of hydrodynamic friction force after texturing was less affected by the liner deformation. Figure 11 shows the boundary friction forces in the groove textured RLC and untextured RLC for different maximum liner deformations when the crank angle $\theta$ was $360^{\circ}$. Different from the results in Figure 10, the grooves on the ring were observed to increase the boundary friction force, and the increase percentages of peak boundary friction force were about $63.57 \%, 62.17 \%$, $47.06 \%$, and $45.83 \%$ when the maximum liner deformations were $0,10,20$, and $30 \mu \mathrm{m}$.

Figure 12 shows the reductions of the average power dissipation and the FMEP value after texturing the grooves on the ring for various maximum liner deformations. It was observed that the ring grooves reduced the average power dissipation and FMEP value effectively. In detail, when the maximum liner deformations were $0,10,20$, and $30 \mu \mathrm{m}$, the decreased percentages of the average power dissipation were about $7.93 \%, 7.94 \%, 7.45 \%$, and $6.93 \%$; the decreased percentages of the FMEP value were about $6.05 \%, 6.08 \%, 5.70 \%$, and $5.19 \%$. Furthermore, the decreased percentages of the average power dissipation and FMEP value were the decreasing functions of the maximum liner deformation when the liner deformation was considered (i.e., the value of $\Delta \mathrm{c}>0 \mu \mathrm{m}$ ).

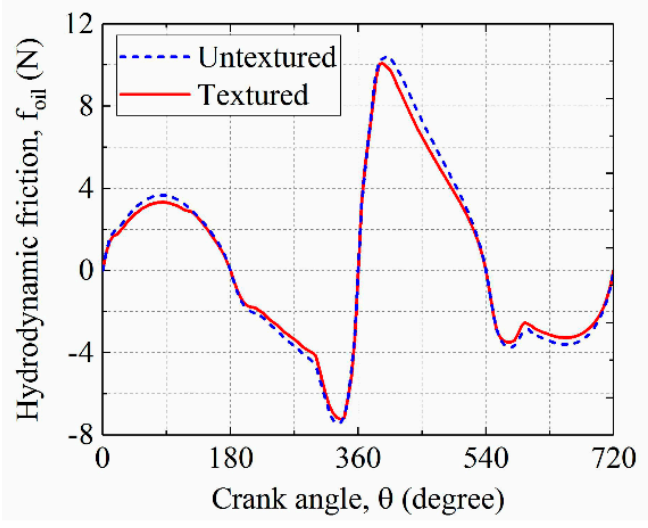

(a)

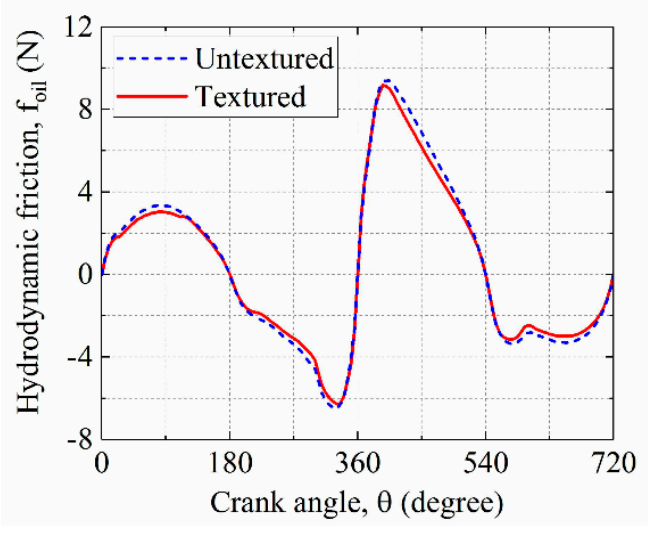

(c)

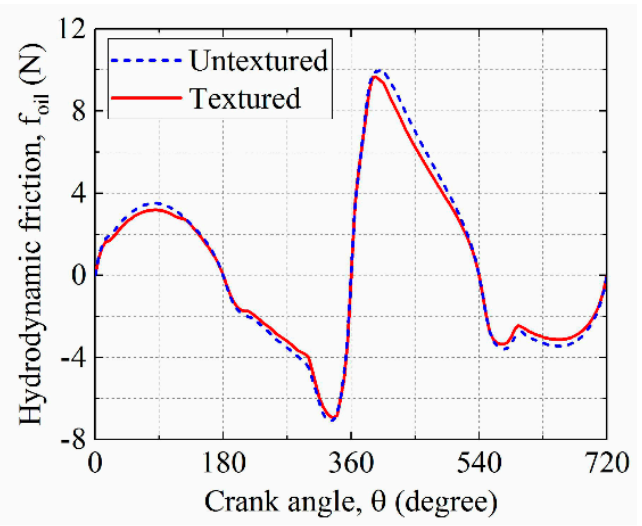

(b)

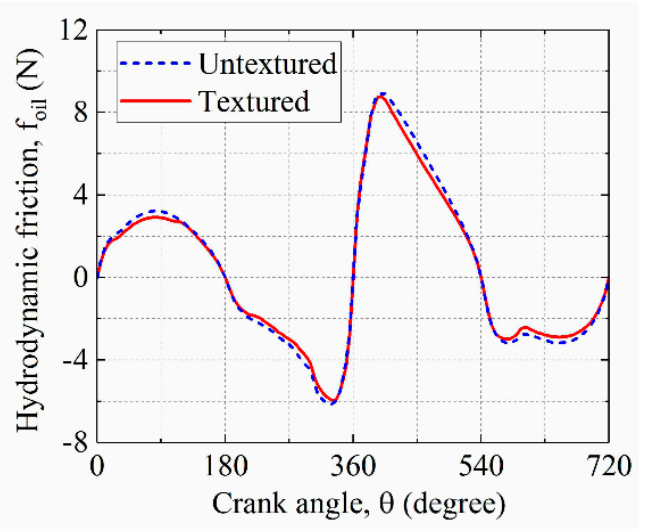

(d)

Figure 10. Hydrodynamic friction forces in the textured RLC and untextured RLC: (a) $\Delta \mathrm{c}$ is $0 \mu \mathrm{m}$; (b) $\Delta \mathrm{c}$ is $10 \mu \mathrm{m}$; (c) $\Delta \mathrm{c}$ is $20 \mu \mathrm{m}$; and (d) $\Delta \mathrm{c}$ is $30 \mu \mathrm{m}$. 
Table 3. Reduction percentages of the hydrodynamic friction force at the middle of strokes for different maximum liner deformations.

\begin{tabular}{ccccc}
\hline \multirow{2}{*}{$\begin{array}{c}\text { Maximum Deformation } \\
\text { of Liner, } \Delta \mathbf{c}\end{array}$} & Intake Stroke & Compression Stroke & Power Stroke & Exhaust Stroke \\
\cline { 2 - 4 } & $9.41 \%$ & $8.72 \%$ & $10.99 \%$ & $8.54 \%$ \\
$0 \mu \mathrm{m}$ & $9.45 \%$ & $8.82 \%$ & $11.06 \%$ & $8.80 \%$ \\
$10 \mu \mathrm{m}$ & $9.18 \%$ & $8.47 \%$ & $10.20 \%$ & $8.67 \%$ \\
$20 \mu \mathrm{m}$ & $9.11 \%$ & $8.27 \%$ & $9.15 \%$ & $8.64 \%$ \\
$30 \mu \mathrm{m}$ & & & & \\
\hline
\end{tabular}

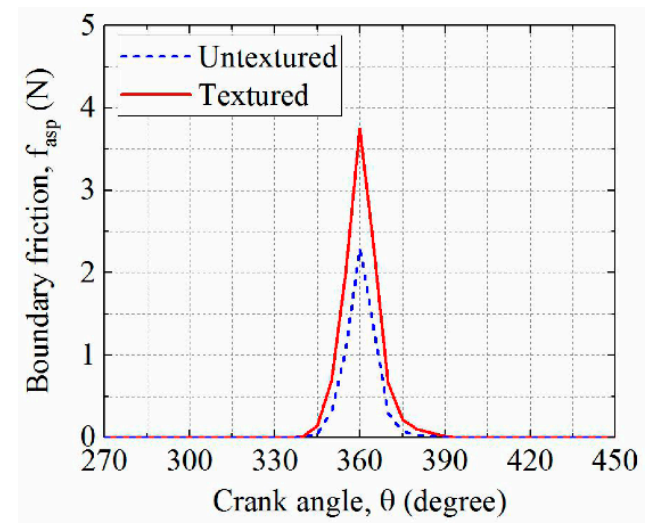

(a)

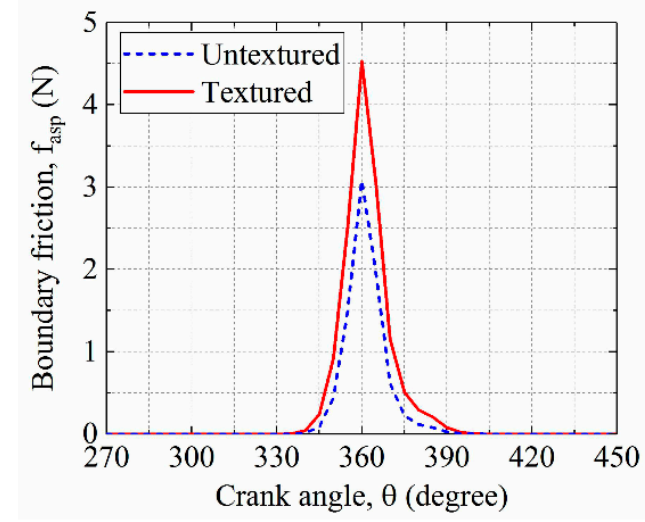

(c)

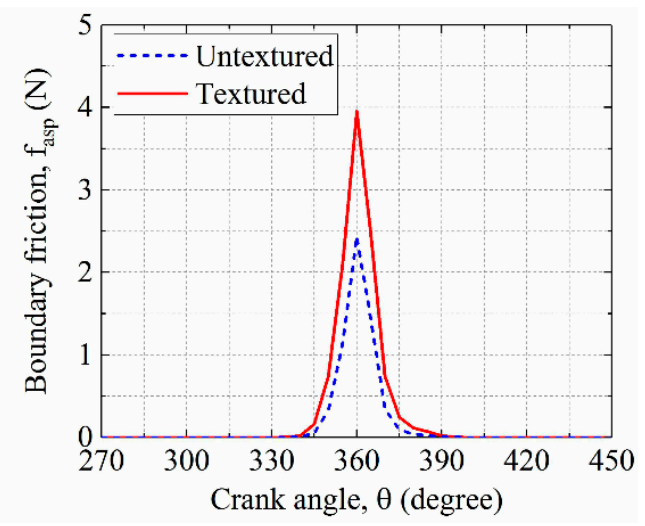

(b)

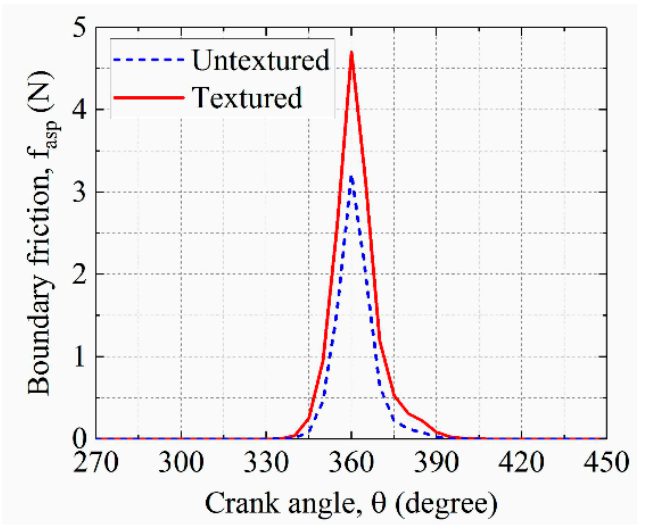

(d)

Figure 11. Boundary friction forces in the textured RLC and untextured RLC: (a) $\Delta \mathrm{c}$ is $0 \mu \mathrm{m} ;$ (b) $\Delta \mathrm{c}$ is $10 \mu \mathrm{m}$; (c) $\Delta \mathrm{c}$ is $20 \mu \mathrm{m}$; and (d) $\Delta \mathrm{c}$ is $30 \mu \mathrm{m}$.

Figure 13 shows the average power dissipation caused by the hydrodynamic friction and the boundary friction for different maximum liner deformations. It was observed that the average power dissipation caused by the hydrodynamic friction was larger than that caused by the boundary friction. Furthermore, after texturing grooves on the ring, the average power dissipation caused by the hydrodynamic friction was reduced, and the average power dissipation caused by the boundary friction was increased. In details, when the maximum liner deformations were $0,10,20$, and $30 \mu \mathrm{m}$, the decreased percentages of the average power dissipation caused by the hydrodynamic friction were about $8.07 \%, 8.10 \%, 7.70 \%$, and $7.20 \%$, and the increase percentages of the average power dissipation caused by the boundary friction were about $111.5 \%, 109.9 \%, 98.81 \%$, and $99.82 \%$. 


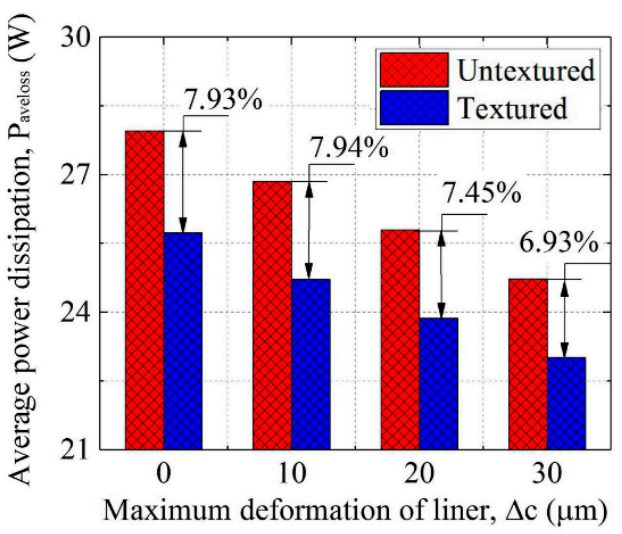

(a)

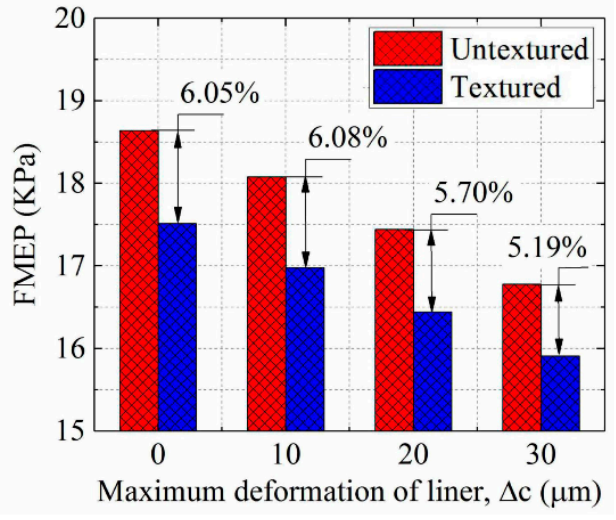

(b)

Figure 12. Reduced percentages of the average power dissipation and friction mean effective pressure (FMEP) value after texturing grooves on the ring for different maximum liner deformations: (a) Average power dissipation; (b) FMEP value.

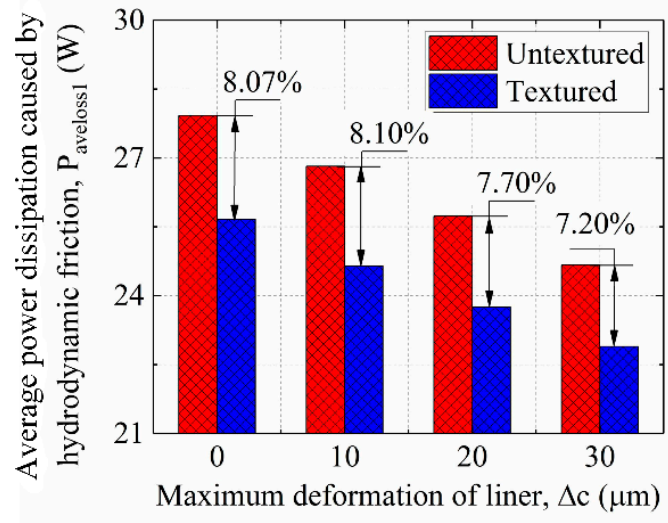

(a)

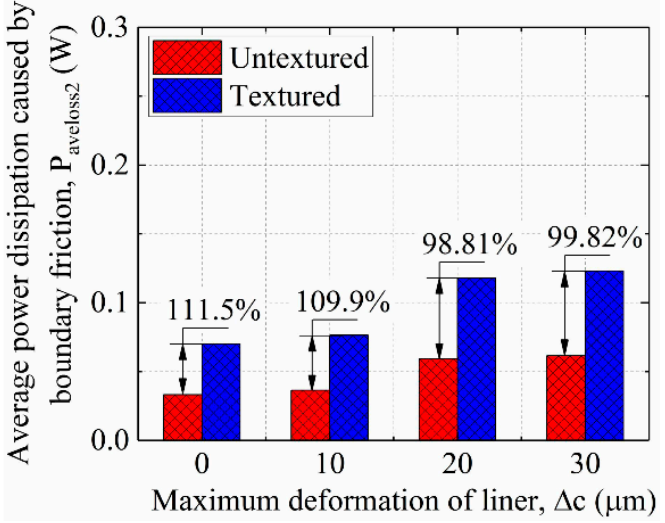

(b)

Figure 13. Average power dissipation caused by the hydrodynamic friction and boundary friction for different maximum deformations of liner: (a) Average power dissipation caused by the hydrodynamic friction; (b) average power dissipation caused by boundary friction.

\subsection{Effect of Liner Temperature}

The hydrodynamic and boundary friction forces in the groove textured RLC for different liner temperatures are shown in Figure 14. It was observed that the difference of hydrodynamic friction force among different liner temperatures was large, especially when the crank angles $\theta$ were 90 , 270,450 , and $630^{\circ}$. Furthermore, when the crank angles $\theta$ were 360 and $540^{\circ}$, the boundary friction force appeared, and the boundary friction force was an increasing function of the liner temperature. The results demonstrate that the liner temperature has significant effect on friction.

To evaluate the friction-reducing effect of the grooves at different liner temperatures, the friction forces in the textured RLC and untextured RLC were calculated. Figure 15 shows the hydrodynamic friction forces when the liner temperatures were $60,80,100$, and $120^{\circ} \mathrm{C}$. It can be seen that the grooves on the ring reduced the hydrodynamic friction force, and a large reduction was observed when the crank angles $\theta$ were $90,270,450$, and $630^{\circ}$. Compared with the liner temperature of $60^{\circ} \mathrm{C}$, the differences of hydrodynamic friction force between the textured RLC and untextured RLC were relatively small when the liner temperature was greater than or equal to $80^{\circ} \mathrm{C}$. Furthermore, when the liner temperature was $120^{\circ} \mathrm{C}$, the reduction of hydrodynamic friction force after texturing grooves on the ring was mainly observed on the power stroke and the exhaust stroke. Figure 16 shows the boundary friction forces for various liner temperatures. The grooves on the ring were observed to 
increase the boundary friction force, and the increase percentages of peak boundary friction force were about $92.23 \%, 50.43 \%, 26.84 \%$, and $14.30 \%$ when the liner temperatures were $60,80,100$, and $120^{\circ} \mathrm{C}$.

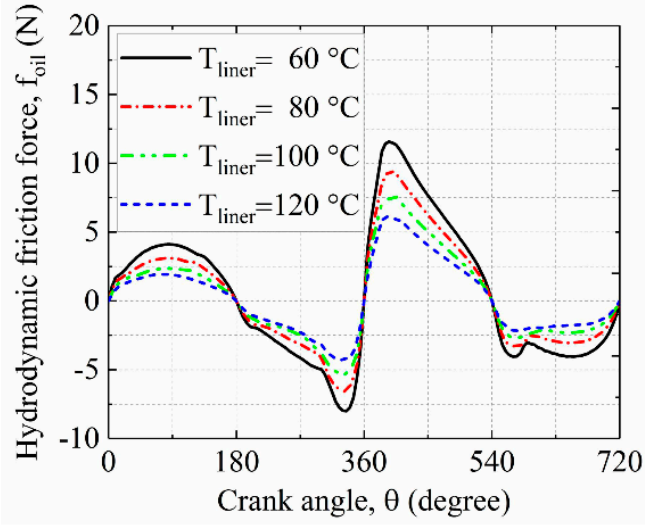

(a)

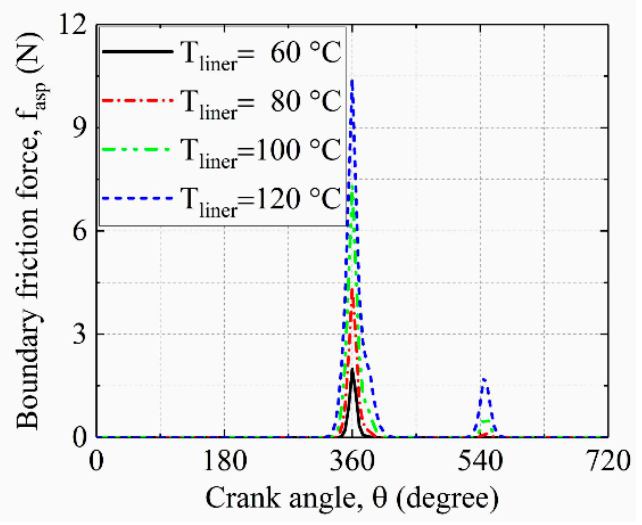

(b)

Figure 14. Friction forces in the groove textured RLC for different liner temperatures: (a) Hydrodynamic friction force; (b) boundary friction force.

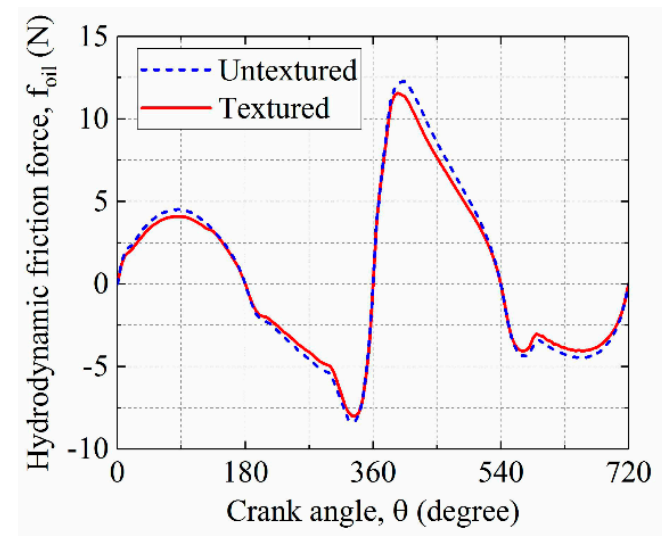

(a)

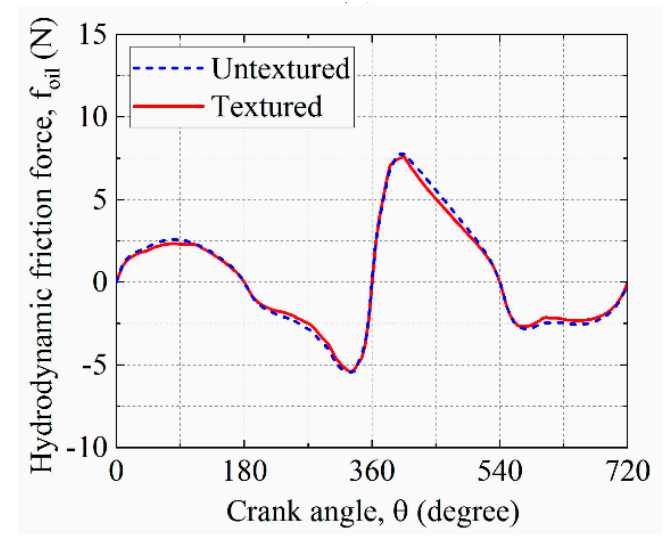

(c)

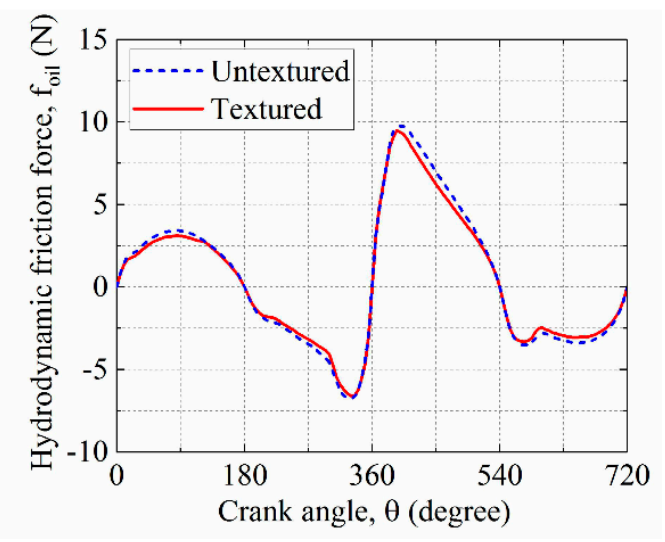

(b)

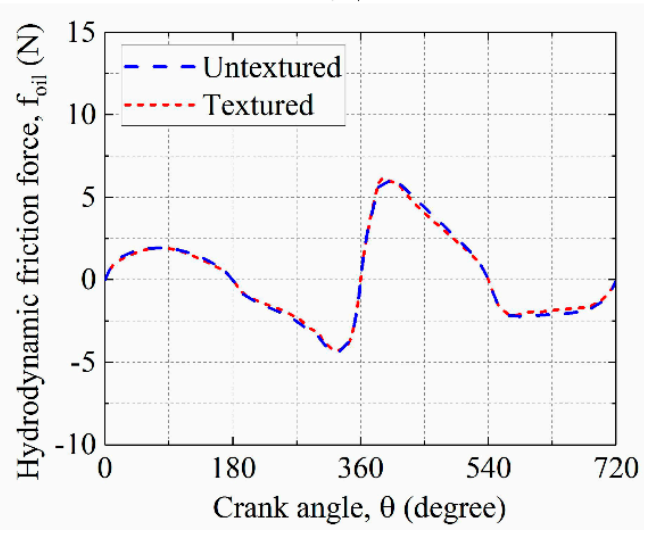

(d)

Figure 15. Hydrodynamic friction forces of the textured RLC and untextured RLC: $(\mathbf{a}) \mathrm{T}_{\text {liner }}$ is $60^{\circ} \mathrm{C}$; (b) $\mathrm{T}_{\text {liner }}$ is $80^{\circ} \mathrm{C}$; (c) $\mathrm{T}_{\text {liner }}$ is $100{ }^{\circ} \mathrm{C}$; and (d) $\mathrm{T}_{\text {liner }}$ is $120^{\circ} \mathrm{C}$. 


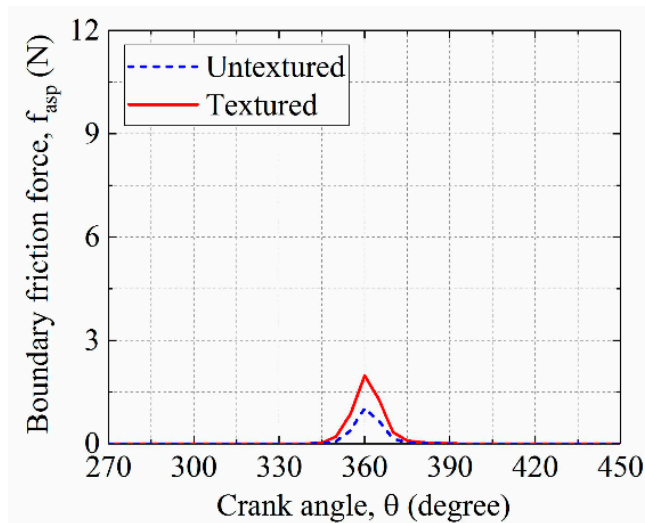

(a)

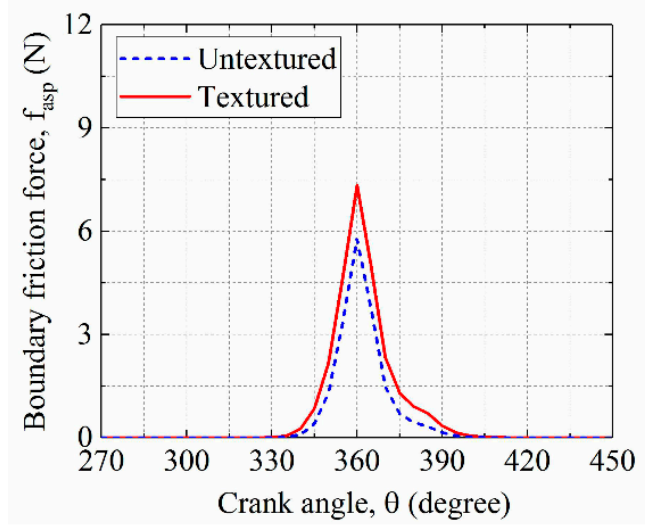

(c)

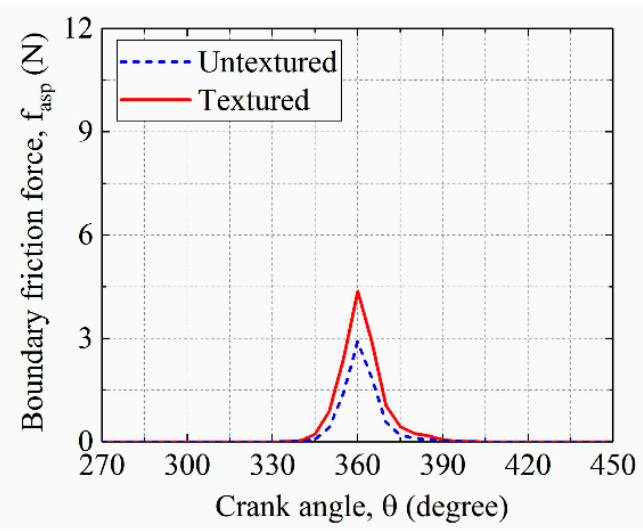

(b)

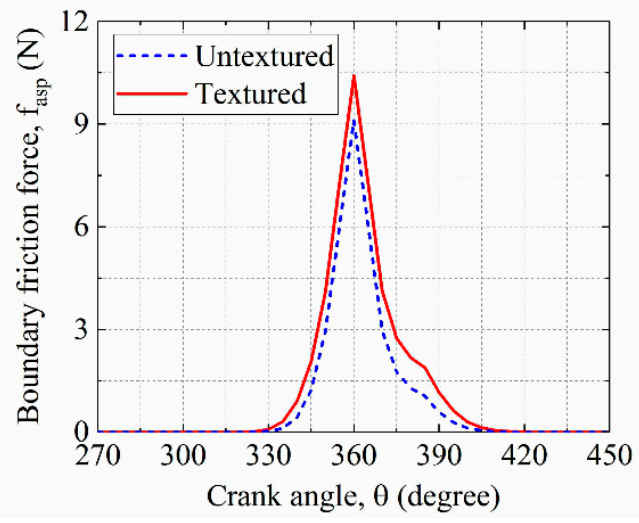

(d)

Figure 16. Boundary friction forces of the textured RLC and untextured RLC: $(\mathbf{a}) \mathrm{T}_{\text {liner }}$ is $60^{\circ} \mathrm{C}$; $(\mathbf{b}) \mathrm{T}_{\text {liner }}$ is $80{ }^{\circ} \mathrm{C}$; (c) $\mathrm{T}_{\text {liner }}$ is $100{ }^{\circ} \mathrm{C}$; (d) $\mathrm{T}_{\text {liner }}$ is $120^{\circ} \mathrm{C}$.

Figure 17a shows the power dissipation of the groove textured RLC at different liner temperatures. A large difference in the power dissipation among various liner temperatures was observed, and the power dissipation decreased with the increase of the liner temperature. This is because that the hydrodynamic friction force increased with the decrease of liner temperature. This result indicates that the liner temperature significantly affected the power dissipation of the textured RLC. To evaluate the reduction of power dissipation after texturing grooves on the ring, the average power dissipation of the textured RLC and untextured RLC were compared, and the compared results are shown in Figure $17 \mathrm{~b}$. It can be observed that the average power dissipation of the textured RLC was lower than that of the untextured RLC. When the liner temperatures were $60,80,100$, and $120^{\circ} \mathrm{C}$, the reductions of average power dissipation were $8.58 \%, 7.85 \%, 6.43 \%$, and $3.93 \%$. These results demonstrate that the grooves on the ring can greatly reduce the power dissipation of the RLC, and the reduction of average power dissipation was large when the liner temperature was low.

Figure 18 shows the average power dissipation caused by the hydrodynamic friction and boundary friction for different liner temperatures. It was observed that the grooves on the ring decreased the average power dissipation caused by the hydrodynamic friction, and the decrease percentage was a decreasing function of the liner temperature. However, the grooves on the ring also increased the average power dissipation caused by the boundary friction, and the increase percentage was also a decreasing function of the liner temperature. 


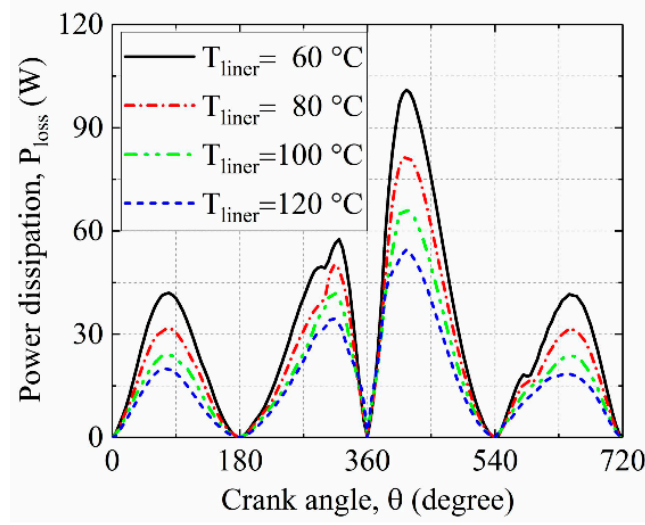

(a)

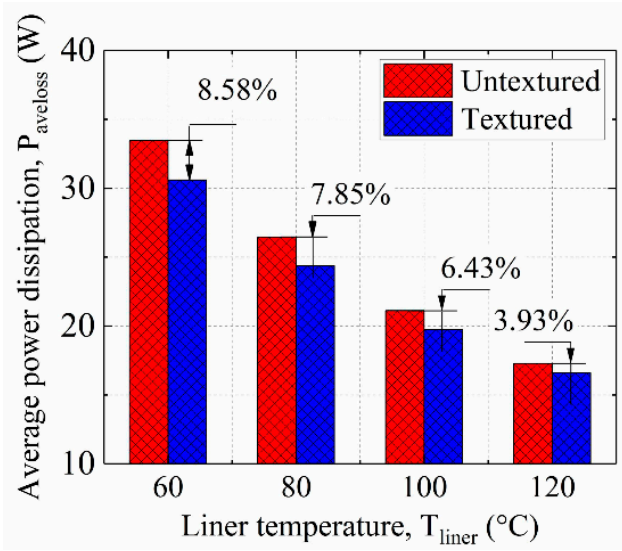

(b)

Figure 17. Power dissipation and average power dissipation of the textured RLC for different liner temperatures: (a) Power dissipation; (b) average power dissipation.

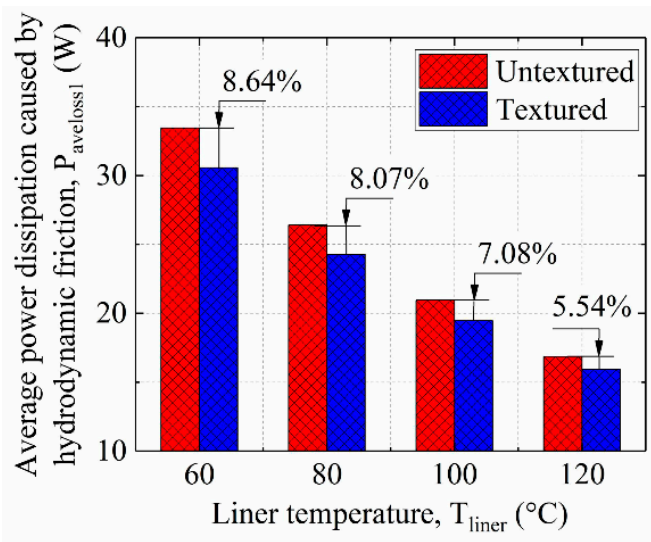

(a)

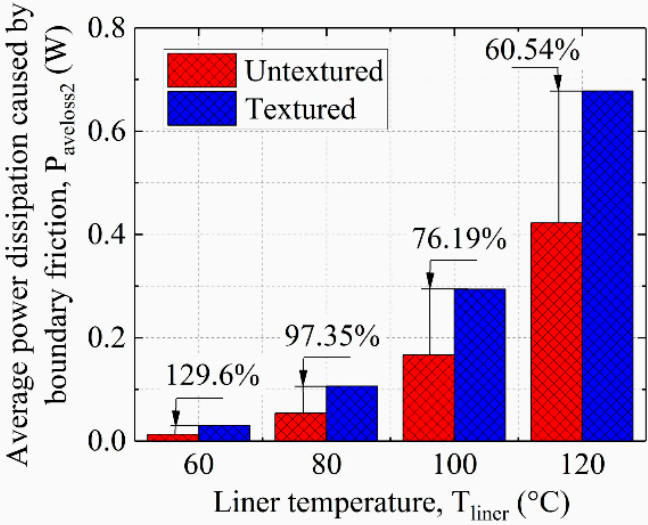

(b)

Figure 18. Average power dissipation caused by the hydrodynamic friction and boundary friction for different liner temperatures: (a) Average power dissipation caused by the hydrodynamic friction; (b) average power dissipation caused by the boundary friction.

Table 4 gives the FMEP values of the textured RLC and untextured RLC for various liner temperatures. In Table 4, the FMEP value decreases with the increase of the liner temperature. Moreover, the FMEP value was greatly reduced after texturing the grooves on the ring, and the reduced percentage of the FMEP value was a decreasing function of the liner temperature. This indicates that the grooves on the ring can significantly reduce the friction dissipation of the RLC, especially at low liner temperature.

Table 4. FMEP values in the textured RLC and untextured RLC for different liner temperatures.

\begin{tabular}{cccc}
\hline \multirow{2}{*}{$\begin{array}{c}\text { Liner Temperature, } \\
\mathbf{T}_{\text {liner }}\end{array}$} & \multicolumn{2}{c}{ FMEP Value } & \multirow{2}{*}{ Reduce Percentage } \\
\cline { 2 - 3 } & Textured Ring & Untextured Ring & \\
\hline $60^{\circ} \mathrm{C}$ & 21.25 & 23.45 & $9.38 \%$ \\
$80^{\circ} \mathrm{C}$ & 16.77 & 18.36 & $8.66 \%$ \\
$100^{\circ} \mathrm{C}$ & 13.42 & 14.52 & $7.58 \%$ \\
$120^{\circ} \mathrm{C}$ & 11.09 & 11.71 & $5.29 \%$ \\
\hline
\end{tabular}

\section{Conclusions}

A mathematical model was proposed to investigate the frictional characteristics of the groove textured RLC with a consideration of the liner deformation and the coexistence of different conditions 
of lubrication (i.e., fully flooded and starved). Based on the model, the effects of liner deformation and temperature on the frictional characteristics of the textured RLC were investigated. Furthermore, the friction-reducing effect of the ring grooves was also evaluated for different liner temperatures and deformations. According to the numerical results obtained in this study, the main conclusions can be made as follows:

1. Liner deformation and temperature affect the frictional characteristics of the groove textured RLC significantly. Compared with the groove textured RLC with ideal circular liner, the groove textured RLC with deformed liner had low friction dissipation and power dissipation. Furthermore, the friction dissipation and power dissipation of the groove textured RLC decreased with the increase of the liner temperature.

2. The grooves on the ring can effectively reduce the hydrodynamic friction force, power dissipation, and friction dissipation, and the reductions of average power dissipation and friction dissipation had a close relation to the liner deformation and temperature. In detail, for the groove textured RLC, the reduction percentages of the average power dissipation and friction dissipation increased with the decreases of the maximum liner deformation and liner temperature. However, when the groove textured RLC was under the mixed regime of lubrication, the grooves on the ring increased the boundary friction force.

It should be noted that these conclusions were made based on the numerical results in this study. The RLC with grooves under practical working conditions will show other complex characteristics (e.g., the dynamic liner deformation caused by piston slap). The experimental validation and investigation on the frictional performance of the RLC with grooves need to be conducted further. Moreover, the geometry optimization on the grooves was not considered in this study, and the asperity heights on the RLC surfaces were assumed to be Gaussian distributed. The optimization on the groove geometry and the frictional performance analysis on the groove textured RLC with non-Gaussian surfaces can also be considered for future directions of this research.

Author Contributions: Conceptualization, C.L.; methodology, C.L. and Y.L.; software, Y.Z.; validation, L.T. and C.G.; formal analysis, C.L.; investigation, Y.L.; resources, Y.L. and N.M.; data curation, Y.Z. and L.T.; writing-original draft preparation, C.L.; writing-review and editing, C.L. and Y.L.; visualization, C.L.; supervision, Y.Z. and N.M.; project administration, Y.L. and C.L.; funding acquisition, Y.L. and C.L.

Funding: This research was funded by the National Natural Science Foundation of China (Grant No. 51775428), the Open Project of State Key Laboratory of Digital Manufacturing Equipment and Technology (Grant No. DMETKF2017014), the Project of PhD Innovation Foundation of Xi'an University of Technology (Grant No. 310-252071701).

Conflicts of Interest: The authors declare no conflict of interest.

\section{References}

1. Checo, H.M.; Ausas, R.F.; Jai, M.; Cadalen, J.P.; Choukroun, F.; Buscaglia, G.C. Moving textures: Simulation of a ring sliding on a textured liner. Tribol. Int. 2014, 72, 131-142. [CrossRef]

2. Mezghani, S.; Demirci, I.; Zahouani, H.; Mansori, M.E. The effect of groove texture patterns on piston-ring pack friction. Precis. Eng. 2012, 36, 210-217. [CrossRef]

3. Gu, C.X.; Meng, X.H.; Xie, Y.B.; Yang, Y.M. Effect of surface texturing on ring/liner friction under starved lubrication. Tribol. Int. 2016, 94, 591-605. [CrossRef]

4. Mishara, P.; Ramkumar, P. Effect of additives on a surface textured piston ring-cylinder liner system. Tribol. Mater. Surf. Interfaces 2019, 13, 67-75. [CrossRef]

5. Usman, A.; Park, C.W. Modeling and simulation of frictional energy loss in mixed lubrication of a textured piston compression ring during warm-up of spark ignition engine. Int. J. Engine Res. 2017, 18, $293-307$. [CrossRef]

6. Francisco, J.P.; Vl descu, S.C.; Reddyhoff, T.; Dini, D. Transient experimental and modelling studies of laser-textured micro-grooved surfaces with a focus on piston-ring cylinder liner contacts. Tribol. Int. 2017, $113,125-136$. 
7. Meng, F.M.; Zhang, Y.Y.; Hu, Y.Z.; Wang, H. Numerical study of influences of hard particles in lubricant on tribological performances of the piston ring. Proc. Inst. Mech. Eng. Part C J. Mech. Eng. Sci. 2007, 221, 361-372. [CrossRef]

8. Ronen, A.; Etsion, I.; Kligerman, Y. Friction-reducing surface-texturing in reciprocating automotive components. Tribol Trans. 2001, 44, 359-366. [CrossRef]

9. Kligerman, Y.; Etsion, I.; Shinkarenko, A. Improving tribological performance of piston rings by partial surface texturing. ASME J. Tribol. 2005, 127, 632-638. [CrossRef]

10. Caciu, C.; Decencière, E.; Jeulin, D. Parametric optimization of periodic textured surfaces for friction reduction in combustion engines. Tribol. Trans. 2008, 51, 533-541. [CrossRef]

11. Noutary, M.P.; Biboulet, N.; Lubrecht, A.A. A robust piston ring lubrication solver: Influence of liner groove shape, depth and density. Tribol. Int. 2016, 100, 35-40. [CrossRef]

12. Ezhilmaran, V.; Vasa, N.J.; Vijayarahavan, L. Investigation on generation of laser assisted dimples on piston ring surface and influence of dimple parameters on friction. Surf. Coat. Tech. 2018, 335, 314-326. [CrossRef]

13. Usman, A.; Park, C.W. Optimizing the tribological performance of textured piston ring-liner contact for reduced frictional losses in SI engine: Warm operating conditions. Tribol. Int. 2016, 99, 224-236. [CrossRef]

14. Morris, N.; Rahmani, R.; Rahnejat, H.; King, P.D.; Howell-Smith, S. A numerical model to study the role of surface textures at top dead center reversal in the piston ring to cylinder liner contact. ASME J. Tribol. 2016, 138, 021703. [CrossRef]

15. Yin, B.F.; Sun, S.; Wang, B.W.; Qian, Y.Q. Numerical research on tribological performance of textured liner surface under different combustion modes. ASME J. Eng. Gas Turb. Power. 2017, 139, 011504. [CrossRef]

16. Liu, C.; Lu, Y.J.; Zhang, Y.F.; Li, S.; Müller, N. Numerical study on the lubrication performance of compression ring-cylinder liner system with spherical dimples. PLoS ONE 2017, 12, e0181574. [CrossRef] [PubMed]

17. Söderfjäll, M.; Larsson, R.; Marklund, P.; Almqvist, A. Texture-induced effects causing reduction of friction in mixed lubrication for twin land oil control rings. Proc. Inst. Mech. Eng. Part J J. Eng. Tribol. 2018, 232, 166-178. [CrossRef]

18. Meng, X.H.; Gu, C.X.; Xie, Y.B.; Li, W.X. A two-dimensional starved lubrication analysis method for textured surfaces. Int. J. Engine Res. 2016, 17, 1062-1076. [CrossRef]

19. Gu, C.X.; Meng, X.H.; Xie, Y.B.; Kong, X.L. Performance of surface texturing during start-up under starved and mixed lubrication. ASME J. Tribol. 2017, 139, 011702. [CrossRef]

20. Gu, C.X.; Meng, X.H.; Zhang, D. Analysis of the coated and textured ring/liner conjunction based on a thermal mixed lubrication model. Friction 2018, 6, 420-431. [CrossRef]

21. Usman, A.; Cheema, T.A.; Park, C.W. Tribological performance evaluation and sensitivity analysis of piston ring lubricating film with deformed cylinder liner. Proc. Inst. Mech. Eng. Part J J. Eng. Tribol. 2015, 229, 1455-1468. [CrossRef]

22. Rahmani, R.; Theodossiades, S.; Rahnejat, H.; Fitzsimons, B. Transient elastohydrodynamic lubrication of rough new or worn piston compression ring conjunction with an out-of-round cylinder bore. Proc. Inst. Mech. Eng. Part J J. Eng. Tribol. 2012, 226, 284-305. [CrossRef]

23. Overgaard, H.; Klit, P.; Vølund, A. Investigation of different piston ring curvatures on lubricant transport along cylinder liner in large two-stroke marine diesel engines. Proc. Inst. Mech. Eng. Part J J. Eng. Tribol. 2018, 232, 85-93. [CrossRef]

24. Li, G.X.; Gu, F.S.; Wang, T.; Lu, X.C.; Zhang, L.; Zhang, C.F.; Ball, A. An improved lubrication model between piston rings and cylinder liners with consideration of liner dynamic deformations. Energies 2017, 10, 2122. [CrossRef]

25. Liu, C.; Lu, Y.J.; Zhang, Y.F.; Li, S.; Kang, J.X.; Müller, N. Numerical study on the tribological performance of ring/liner system with consideration of oil transport. ASME J. Tribol. 2019, 141, 011701. [CrossRef]

26. Rahmani, R.; Rahnejat, H.; Fitzsimons, B.; Dowson, D. The effect of cylinder liner operating temperature on frictional loss and engine emissions in piston ring conjunction. Appl. Energy 2017, 191, 568-581. [CrossRef]

27. Dunaevsky, V.V. Analysis of distortions of cylinders and conformability of piston rings. Tribol. Trans. 1990, 33, 33-40. [CrossRef]

28. Ma, M.T.; Smith, E.H.; Sherrington, I. Analysis of lubrication and friction for a complete piston-ring pack with an improved oil availability model part 2: Circumferentially variable film. Proc. Inst. Mech. Eng. Part J J. Eng. Tribol. 1997, 211, 17-27. [CrossRef] 
29. Usman, A.; Park, C.W. Numerical investigation of tribological performance in mixed lubrication of textured piston ring-liner conjunction with a non-circular cylinder bore. Tribol. Int. 2017, 105, 148-157. [CrossRef]

30. Usman, A.; Park, C.W. Mixed lubrication of piston compression ring with deformed cylinder liner during warm-up of spark ignition engine. Proc. Inst. Mech. Eng. Part J J. Eng. Tribol. 2016, 230, 1288-1309. [CrossRef]

31. Zhu, X.P.; Bai, S.; Chen, Y.; Song, H.N. Deformation analysis of the cylinder liner based on mechanical-thermal coupling. Des. Manuf. Diesel Engine 2013, 3, 9-14.

32. Gu, C.X.; Meng, X.H.; Xie, Y.B.; Zhang, D. Mixed lubrication problems in the presence of textures: An efficient solution to the cavitation problem with consideration of roughness effects. Tribol. Int. 2016, 103, 516-528. [CrossRef]

33. Patir, N.; Cheng, H.S. An average flow model for determining effects of three-dimensional roughness on partial hydrodynamic lubrication. ASME J. Lubr. Technol. 1978, 100, 12-17. [CrossRef]

34. Patir, N.; Cheng, H.S. Application of average flow model to lubrication between rough sliding surfaces. ASME J. Lubr. Technol. 1979, 101, 220-229. [CrossRef]

35. Wu, C.; Zheng, L. An average Reynolds equation for partial film lubrication with a contact factor. ASME J Tribol. 1989, 111, 220-229. [CrossRef]

36. Morris, N.; Rahmani, R.; Rahnejat, H.; King, P.D.; Fitzsimons, B. Tribology of piston compression ring conjunction under transient thermal mixed regime of lubrication. Tribol. Int. 2013, 59, 248-258. [CrossRef]

37. Gulwadi, S.D. A mixed lubrication and oil transport model for piston rings using a mass-conserving algorithm. ASME J. Eng. Gas Turb. Power. 1998, 120, 199-208. [CrossRef]

38. Morris, N.; Mohammadpour, M.; Rahmani, R.; Johns-Rahnejat, P.M.; Rahnejat, H.; Dowson, D. Effect of cylinder deactivation on tribological performance of piston compression ring and connecting rod bearing. Tribol. Int. 2018, 120, 243-254. [CrossRef]

39. Pu, W.; Zhu, D.; Wang, J.X. A starved mixed elastohydrodynamic lubrication model for the prediction of lubrication performance, friction and flash temperature with arbitrary entrainment angle. ASME J. Tribol. 2018, 140, 031501. [CrossRef]

40. Wang, F.; Zhao, S.X. The research on the properties of the journal bearing based on the P- $\theta$ model. Mach. Des. Manuf. 2016, 11, 76-79.

41. Gu, C.X.; Meng, X.H.; Xie, Y.B.; Li, P. A study on the tribological behavior of surface texturing on the nonflat piston ring under mixed lubrication. Proc. Inst. Mech. Eng. Part J J. Eng. Tribol. 2016, 230, 452-471. [CrossRef] 